\title{
Sensitivity of the Northern Hemisphere blocking frequency to the detection index
}

\author{
F. J. Doblas-Reyes ${ }^{1}$ \\ Departmento de Fisica de la Tierra, Astronomia y Astrofisica II, Facultad de Ciencias Fisicas, Universidad Complutense, \\ Madrid, Spain
}

\section{J. Casado and M. A. Pastor}

Instituto Nacional de Meteorología, Madrid, Spain

Received 27 December 2000; revised 16 July 2001; accepted 27 July 2001; published 16 January 2002.

[1] The sensitivity of Northern Hemisphere blocking features to the use of two different blocking indices is investigated using European Centre for Medium-Range Weather Forecasts (ECMWF) reanalyses (ERA) and data from a climate simulation carried out with the atmospheric general circulation model Action de Recherche, Petite Echelle, Grande Echelle ARPEGE. The seasonal cycle of blocking frequency shows a good agreement between both indices, for both analyses and model, when the seasonal cycle of the 500-hPa geopotential height is previously removed from the data. Furthermore, the blocking frequency seasonal cycle agrees well with the 5- to 45-day bandpass- filtered standard deviation (a proxy indicator of blocking activity) seasonal cycle. In contrast to previous results, this demonstrates that a consensus estimate of blocking features may be obtained with two different blocking indices. Nevertheless, some differences in the results from the two indices have been detected, particularly for the Euro-Atlantic blocking. Regional differences suggest that on some occasions, an index may detect blocking events that the other index misses, and vice versa. An important consequence is that uncertainty in blocking interannual variability estimates, which depend on the index used, is expected to be high. The study shows that the model underestimates the blocking frequency regardless of the index used. However, the model proves to be able to simulate realistic blocks when removing an estimate of the geopotential time-mean bias. Blocking drawbacks in the model are interpreted as a consequence of a specific zonal wind forcing associated with a decrease in the frequency of large-scale ridges over the main blocking regions. These results strengthen the interest of analyzing model blocking as a complex phenomenon with regional dynamical differences and tight links with other atmospheric phenomena. INDEX TERMS: 3319 Meteorology and Atmospheric Dynamics: General circulation, 3364 Meteorology and Atmospheric Dynamics: Synoptic-scale meteorology, 3309 Meteorology and Atmospheric Dynamics: Climatology (1620); KEYWORDS: blocking index, intraseasonal variability, model validation, Northern Hemisphere, seasonal cycle

\section{Introduction}

[2] Atmospheric blocking, usually defined as a midlatitude anomalous flow pattern associated with a strong meridional wind component and a consequential split of the jet stream, is an interesting phenomenon from a theoretical point of view and poses a difficult medium-range forecasting problem [Renwick, 1996]. The blocking pattern is characterized by a region of warm air with higher than ambient pressure, so that the situation is essentially recognized by a quasistationary, positive height anomaly relative to a regional mean in which the normal eastward progression of migrating midlatitude weather systems is deflected [Nakamura, 1994]. The associated pressure or geopotential height maximum tends to fluctuate in amplitude and width [Vautard, 1990], and its lifetime usually amounts to several days. Blocking has been studied extensively in the Northern Hemisphere [Rex, 1950; Lejenäs and Økland, 1983; Dole, 1986; Renwick and Wallace, 1998]. Preferred Northern

\footnotetext{
${ }^{1}$ Now at European Centre for Medium-Range Weather Forecasting, Reading, UK.
}

Copyright 2002 by the American Geophysical Union. 0148-0227/02/2000JD000290\$09.00
Hemisphere locations are to the north and east of the Pacific and Atlantic storm tracks. Similar studies for the Southern Hemisphere are much smaller in number [Lejenäs, 1984; Trenberth and Mo, 1985; Rutland and Fuenzalida, 1991; Sinclair, 1996; Marques and Rao, 2000]. A preferred region for blocking action is found on the Australian-New Zealand sector, as well as over the southeast of South America and the southern Indian Ocean. The regional preference of blocking determines much of the space-time variability of midlatitude and subtropical precipitation patterns [Illari, 1984], and in particular, the longest-lasting anomalies are responsible for relatively long drought episodes [Quesada et al., 1995].

[3] Two principal mechanisms of blocking maintenance, considered as a weather regime, have been proposed [D'Andrea, 1999]. Legras and Ghil [1985] assumed that it is associated with stationary solutions of the governing equations, the atmospheric state changing from a solution to another one after some time. In a second approach it can be considered as a result of the feedback of some waves similar to the midlatitude baroclinic waves [Vautard and Legras, 1988] on the mean flow. This process may also explain the slight improvement in the blocking simulation found when model resolution is increased [Tibaldi and Ji, 1983; Doblas-Reyes et al., 1998]. The blocking complexity, due to the strong interactions taking place during its 
lifetime, explains why it is difficult to correctly represent blocking in both numerical weather prediction models [Tracton, 1990; Tibaldi et al., 19941 and climate general circulation models (GCM) [D'Andrea et al., 1996].

[4] GCMs require numerous parameterizations of small-scale physical processes, and they perform well when used for shortterm simulations as in weather forecasting. However, such a high reliability cannot be assumed to hold in climate applications. All atmospheric GCMs exhibit some kind of climatic drift. Furthermore, GCMs used in climate studies differ notably from those used in weather forecasting because they must incorporate slowly varying aspects of the climate system such as interactive ocean and sea-ice variations. Owing to the extra computational requirements, this implies that a climate GCM often has lower resolution or simpler parameterizations than numerical weather prediction models. In this context, some methods for estimating model reliability are required. In order to estimate model performance and model error in midlatitudes, diagnostics of blocking activity on climate GCM outputs have been proposed [e.g., D'Andrea et al., 1996, and references therein]. The ability of climate GCMs to represent blocking as a main source of midlatitude intraseasonal low-frequency (ILF) variability is often assessed. The correct simulation of blocking is important since in order to make relatively long-range forecasts, a model must be able to make blocks with the right amplitude, location, and persistence [Brankovic and Ferranti, 1992; Tibaldi et al., 1994]. Actually, the inability shown by some GCMs to properly enter into a blocked state in a climatic sense is a limiting factor of paramount importance for extended-range forecasting [Pavan and DoblasReyes, 2000].

[5] One of the main obstacles in studying atmospheric blocking in long time series is the definition of blocking itself. This uncertainty is a major difficulty that confronts researchers and hampers intercomparison of scientific results. Hence objective procedures for identifying blocking events are required, although almost all definitions contain some subjectivity [Knox and Hay, 1984; Sausen et al., 1995]. Tibaldi et al. [1990] compared several simulations with different horizontal resolutions. They demonstrated that higher-resolution integrations better predicted the correct evolution of midlatitude anomaly fields during blocking episodes, though their discussion did not take into account the effect of the model basic state in determining blocking features. Thus the influence of midlatitude transients, such as storm tracks, on block formation and maintenance [Tsou and Smith, 1990] should also be taken into account in the analysis of blocking in the simulations. Since the pioneering work of Rex [1950], who formulated a flow anomaly criterion for detecting blocking events, two main types of simple blocking indices have been used. A computationally economic method uses indices based on the meridional gradient of geopotential height [Lejenäs and Økland, 1983; Tibaldi and Molteni, 1990]. A split-up flow pattern is detected by using a certain threshold for the meridional gradient of geopotential height at each longitude. Moreover, the selected events are investigated in a contiguous region to avoid the erroneous classification of small-scale systems. However, empirical parameters, like the latitude at which the meridional gradient is evaluated, become essential for this method, hampering the applicability of the method to different climates. Moreover, one of the major issues in midlatitude climate modeling is whether the model bias is generated in part by the failure of the simulated blocking, this kind of index being unable to answer this question. Using a different approach, Elliott and Smith [1949] computed surface pressure anomalies from the climatological mean and detected the regions where the anomalies exceeded a given threshold for a certain time, offering a straightforward way of blocking identification. The approach has also been used by other authors [Dole and Gordon, 1983; Mullen, 1987; Liu, 1994]. However, the problem of a proper definition of the anomalies has always been present. The dependence of this procedure on some arbitrary parameters, like the definition of the climate mean or the anomaly threshold, represents an important drawback. Finally, as an independent tool, multivariate classification methods based mainly on the objective search for atmospheric weather regimes [Vautard, 1990] have also been used, though the obtained blocking signatures may be dependent on both the algorithm and the data used.

[6] The impact of specific blocking indices in determining the predominant characteristics of blocking in both reality and a climate GCM is discussed in this paper. The scope is to assess the robustness of the blocking features in the real atmosphere regardless of the index used, to compare the performance of the model against a reference, and to set up a framework to estimate significant changes of blocking properties in any model scenario. A comparison of the blocking features obtained using two standard indices based on the two different approaches described in this section is carried out. For the sake of simplicity the comparison has been made for the Northern Hemisphere. The paper is organized as follows: section 2 describes the data sources and the methodology. Some results concerning the basic state of the atmosphere and some midtropospheric features closely related with blocking are presented in section 3. Section 4 describes the blocking features obtained with the two indices. The differences in blocking frequency, lifetime, and location are discussed in section 5, including an intercomparison of the results presented in section 4 that stresses the importance of the basic state. section 6 contains a summary and the outline of the main results.

\section{Data and Blocking Indices}

\subsection{Data Used}

[7] The study is based on two data sets consisting of gridded daily 500-hPa geopotential heights (1200 UT) of 15 winters (1979/ 1980 to 1993/1994). The two data sets are the reanalyses of the European Centre for Medium-Range Weather Forecasts (ECMWF) (ERA) and a 15-year integration of the Action de Recherche, Petite Echelle, Grande Echelle (ARPEGE) GCM.

[8] The ARPEGE GCM was adapted from the numerical weather prediction model developed jointly by ECMWF and Météo-France. The basic climate versions are described by Déqué et al. [1994] (version 0), Déqué and Piedelievre [1995] (version 1), and Doblas-Reyes and Déqué [1998] (version 2). The version used here presents a series of modifications compared with the previous ones. As far as the dynamics are concerned, a semi-Lagrangian advection scheme has been used. It allows for the use of a linear grid instead of a quadratic one. Some new physical parameterizations have been included: new stratiform cloud and precipitation schemes [Ricard and Royer, 1993], prescription of the vertical mixing length making use of a diagnosed mixing- layer height [Holstag and Boville, 1993], a more realistic way of treating convection effects [Lorant and Royer, 2001], variation through the vertical of the convective cloud cover, and finally, modifications in the surface scheme and vegetation parameterization [Douville et al., 2000].

[9] The simulation has been carried out with 45 levels in the vertical and a T63 spectral truncation. Data were available in a grid with 128 longitudes and 64 latitudes. The starting situation was a pseudo 1 January 1979, generated after a 5-year simulation of the GCM with climatological boundary conditions. Prescribed daily sea surface temperatures (SSTs) were linearly interpolated in time from observed monthly mean fields in the period 1979-1993.

[10] For practical purposes the analysis data computed with a T106 truncation $\left(1.125^{\circ}\right.$ spacing grid) have been projected onto a 
regular grid with 128 longitudes and 64 latitudes. Then a space domain ranging from $0^{\circ}$ to $360^{\circ}$ and from $20^{\circ}$ to $90^{\circ} \mathrm{N}$ has been selected. The reduced domain comprises 128 longitudes and 25 latitudes. The Northern Hemisphere seasons have been taken as the 90- to 92-day periods from 1 December to 28 February (winter), 1 March to 31 May (spring), 1 June to 31 August (summer), and 1 September to 30 November (fall).

\subsection{Blocking Indices}

[11] Blocking detection methods might be classified in objective and subjective procedures. Objective detection procedures are based on the use of statistical methods for classifying the atmospheric circulation [Vautard, 1990]. On the other hand, subjective methods are based on both the use of synoptic-scale experience for the design of an automatic detection algorithm and the calibration of a set of parameters. In a rough classification of subjective blocking indices a group of them are based on the value of the geopotential height meridional gradient. A different group uses the geometrical features of the geopotential height anomalies. As an example of the first group, the Tibaldi and Molteni [1990] blocking index (TM index) has been used in this study because it allows us to make comparisons with previous analyses of blocking [ $D^{\prime} A n$ drea et al., 1996; Corti et al., 1997; Tibaldi et al., 1997; Pavan and Doblas-Reyes, 2000].

[12] The analysis has been carried out using the version of the TM blocking index described by D'Andrea et al. [1998]. The geopotential height meridional gradient south (GHGS) and geopotential height gradient north (GHGN) are evaluated for each longitude $\lambda$ at each time step $t$ :

$$
\begin{aligned}
\operatorname{GHGS}(\lambda, t) & =\frac{Z\left(\phi_{0}, \lambda, t\right)-Z\left(\phi_{s}, \lambda, t\right)}{\phi_{0}-\phi_{s}} \\
\operatorname{GHGN}(\lambda, t) & =\frac{Z\left(\phi_{n}, \lambda, t\right)-Z\left(\phi_{0}, \lambda, t\right)}{\phi_{n}-\phi_{0}}
\end{aligned}
$$

where $\phi_{n}=80^{\circ} \mathrm{N}+\Delta ; \phi_{0}=60^{\circ} \mathrm{N}+\Delta ; \phi_{s}=38.75^{\circ} \mathrm{N}+\Delta ; \Delta=m$ $\times 2.8^{\circ} ; m=-2,0$, and 2 ; and $Z(\phi, \lambda, t)$ is the geopotential value at the latitude $\phi$ and longitude $\lambda$ measured at the time step $t$. A given longitude is locally defined as blocked for a specific day if, at least for one of the three values of $\Delta$, the conditions GHGS $>0$ and GHGN $<-5 \mathrm{~m} /{ }^{\circ}$ lat are fulfilled. These parameters produce robust results, although estimates of blocking frequency over the Pacific seem to be slightly sensitive to the latter condition. In addition, as time persistence is an important feature of blocking events, they were defined as those lasting 5 or more days. Nevertheless, some exceptions to this rule have been included in the blocking episodes following D'Andrea et al. [1996]. They include in their analysis the threshold-edge episodes, that is, those that may or may not intermittently fulfill the requirements of the index. Special events of this type are either the sequences of 5 blocked days with the second or third day being nonblocked or the sequences of 6 blocked days with the second or the fourth being the nonblocked day.

[13] The same blocking event may be counted at several points because it generally covers more than one grid point. In order to take into account this feature and given that blocking shows a clear regional preference of formation, three main Northern Hemisphere blocking sectors have been considered. The corresponding longitudinal limits are $60^{\circ} \mathrm{W}-45^{\circ} \mathrm{E}$ for the Euro-Atlantic sector (EU), $45^{\circ} \mathrm{E}-80^{\circ} \mathrm{E}$ for the Siberian sector (SIB), and $152^{\circ} \mathrm{E}-136^{\circ} \mathrm{W}$ for the Pacific sector (PAC). For specific purposes, two other regions over the EU sector have been considered: western Atlantic $60^{\circ} \mathrm{W}-$ $22.5^{\circ} \mathrm{W}$ (WA) and eastern Atlantic $22.5^{\circ} \mathrm{W}-45^{\circ} \mathrm{E}(\mathrm{EA})$. A sector is considered to be blocked if three or more adjacent points (i.e., $9^{\circ}$ broad) over a latitude band are blocked according to the local index defined above. The persistence criterion was then applied, as is usually done in the literature, to define blocking episodes. The separation into regions allows us to decide whether there is any difference between the characteristics of blocking events over several domains.

[14] The empirical parameters of the index, like the latitudes at which the gradient is computed, hamper the application of the index to different climates, as would be also the case of the present climate simulated by a model with some geopotential bias. However, it is extremely useful when time series are short, so that a robust climatology is not available. The use of only a 15 -year period to evaluate the mean blocking features may cause a sampling problem owing to the presence of a strong decadal variability in the number of blocking events. Nevertheless, several authors [Anderson, 1993; D'Andrea et al., 1996] have shown that this period is long enough to assess general blocking features despite the decadal variability of blocking frequency.

[15] The other group of indices mentioned above is based on the detection of local geopotential height maxima and was applied for the first time by Elliott and Smith [1949]. Height anomalies have been often used for automatic identification of blocking events [Dole and Gordon, 1983; Shukla and Mo, 1983; Mullen, 1986; Liu, 1994]. In this study the index described by Sausen et al. [1995] (SKS) has been applied. This index reduces the number of empirical parameters to a minimum, although it requires time series long enough so as to be able to compute a reliable climatology. Before applying the index the mean and the annual cycle have been removed from the time series $Z(\phi, \lambda, t)$. The annual cycle has been removed using the method described in Appendix A. Then the anomaly field is analyzed with a two-step procedure. First, in the space-time domain the contiguous areas with an anomaly higher than a given threshold $Z_{1}$ existing for at least 5 days are sought. Two values are considered adjacent if their longitude, latitude, and time are separated by just one interval, which in our case will be $2.8^{\circ}$ in longitude and latitude and 1 day in time. The points belonging to a contiguous area are also included in the detected blocked region. They are those values belonging to a chain of $k$ values adjacent to one of the two initial values. The second step of the detection process consists of extending the area contiguously to those values where the anomaly exceeds a second threshold $Z_{2}$. The second threshold should be smaller than the first one. Given the strong seasonal cycle of the atmospheric variability [Barnston and van den Dool, 1993], a seasonally dependent set of thresholds as described by Shukla and Mo [1983] and Knox and Hay [1984] would provide better results. However, fixed values for the parameters have been used here $\left(k=5, Z_{1}=300\right.$, and $\left.Z_{2}=250\right)$ so as to keep the comparison as close as possible to other authors' results. These set of values are referred to in the following as reference parameters. In order to take into account the model bias in variability, a model-specific threshold has also been used. The model-specific parameters have been defined as the 98th $(240 \mathrm{~m})$ and 96th $(200 \mathrm{~m})$ percentiles of the model geopotential height anomalies in winter which in the case of ERA coincide with the reference values.

[16] This index does not make any assumption on the latitudes where the phenomenon is found so that it can be applied to both model validation and climate change where blocking may be located in different places than in the actual climate. However, it requires a robust estimation of the mean field. A similar set of indices uses a blocking anomaly pattern to select the anomaly maps that better correlate with it [Liu, 1994; Buongioannini et al., 1999]. The problem with this approach comes from the large phase variations of blocking which avoid the correct detection of blocking events located too far east or west with regard to the target pattern.

\section{Basic State and Intraseasonal Variability}

[17] A description of the basic state of the middle troposphere in the analyses and the model is presented in this section. The 
a)

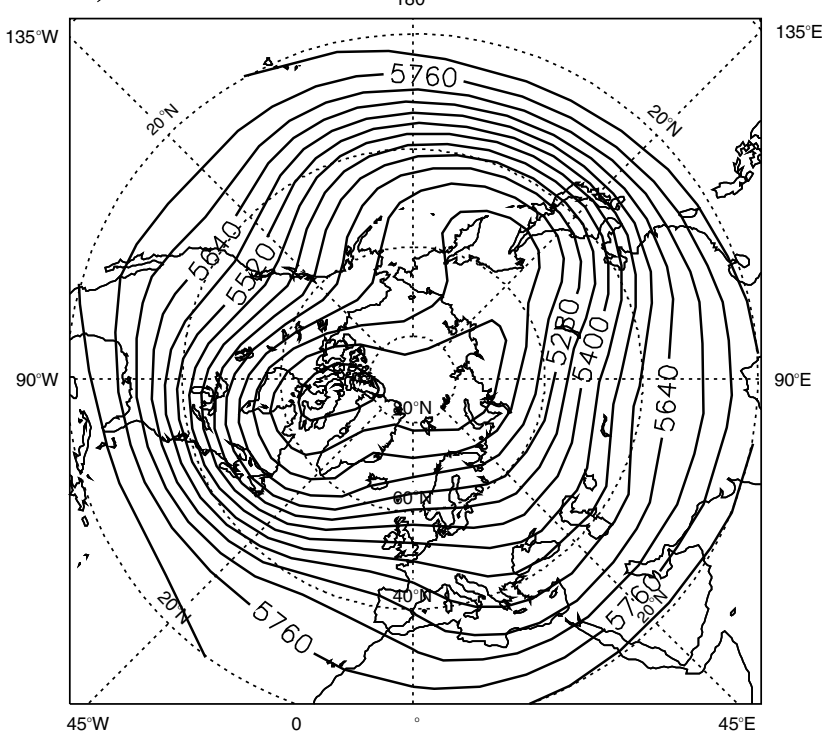

c)

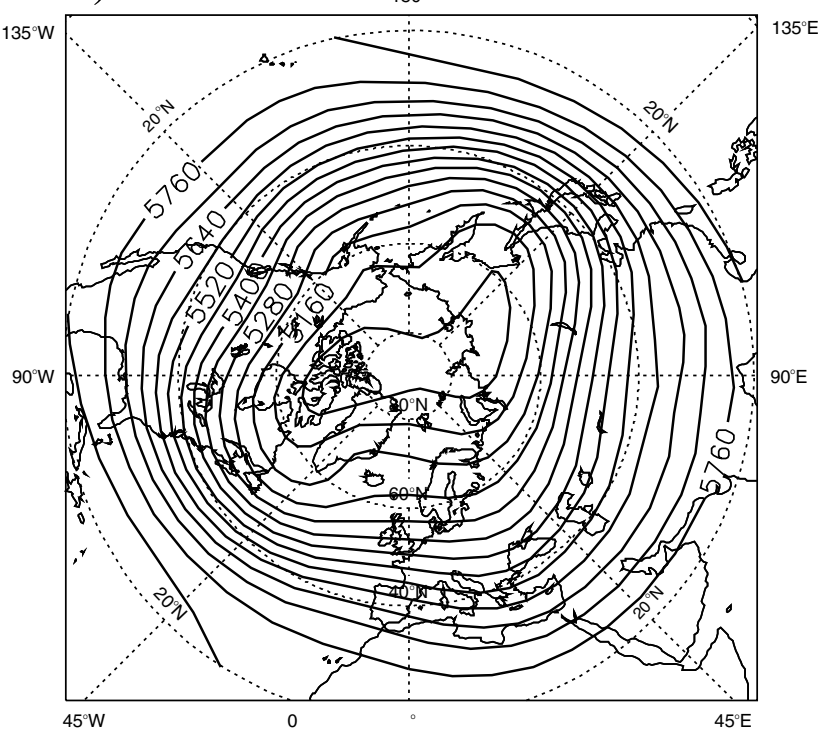

b)

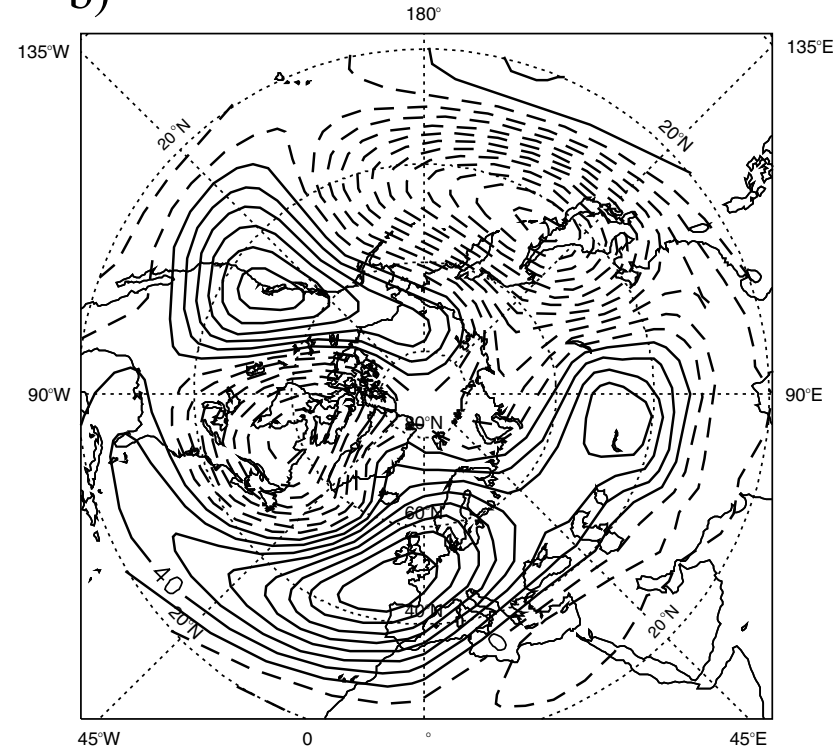

d)

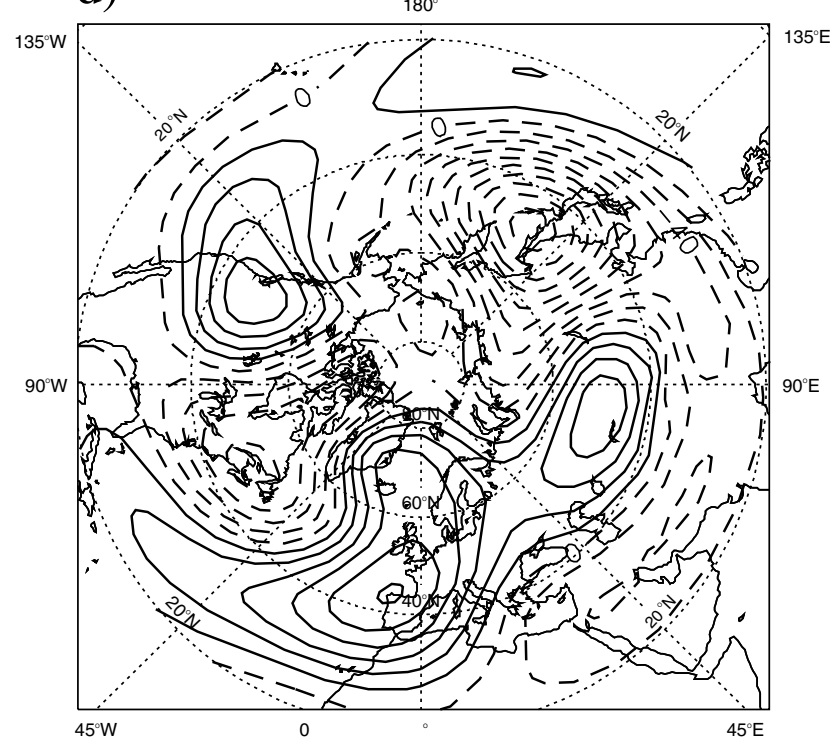

Figure 1. Long-term winter time-mean of $500 \mathrm{hPa}$ geopotential height for (a) the analyses and (c) ARPEGE. Contour interval is $60 \mathrm{~m}$. Eddy component (stationary wave, computed as the zonal mean deviation) for (b) the analyses and (d) ARPEGE. Negative values are dashed. Contour interval is $20 \mathrm{~m}$.

stationary waves and the geopotential height seasonal cycle are two of the features that better characterize the atmospheric background in which blocking develops. For instance, blocking formation tends to be associated with stationary waves amplification [Da Silva and Lindzen, 1993]. Thus the knowledge of the basic state and its evolution might be helpful in the understanding of the different blocking features found in the analyses and the model. Band-pass intraseasonal variability is then described as a measure of the atmospheric activity in the blocking frequency band and is later used as an estimate of the blocking frequency seasonal cycle.

\subsection{Stationary Waves}

[18] One of the most important tropospheric features to be taken into account in blocking analysis is the stationary wave structure. The midlatitude atmospheric circulation of the Northern Hemisphere can be mainly considered as the result of transient disturbances in geographically preferred regions superposed on planetary-scale stationary waves. Stationary waves present a seasonal evolution [Barnston and van den Dool, 1993] in the same way as transient wave fluxes do [Randel and Held, 1991], though this should be more evident near the surface [Held, 1983] because of the seasonal migration of the thermal forcing. The winter time-mean $500-\mathrm{hPa}$ geopotential field for the analyses and the model are shown in Figures 1a and $1 \mathrm{c}$. Departures from the zonal mean (the eddy component), usually considered as good estimates of the stationary waves, are also shown (Figures $1 \mathrm{~b}$ and 1d). Two main jets are observed for the analyses (Figure 1a) over the Atlantic and the Pacific in the same location as the wave troughs. Wave ridges are found over the western part of the continents and over Siberia. The structure of the stationary waves in the other seasons is similar to that in winter, except for a meridional shift of the waves (not shown). During summer the meridional 

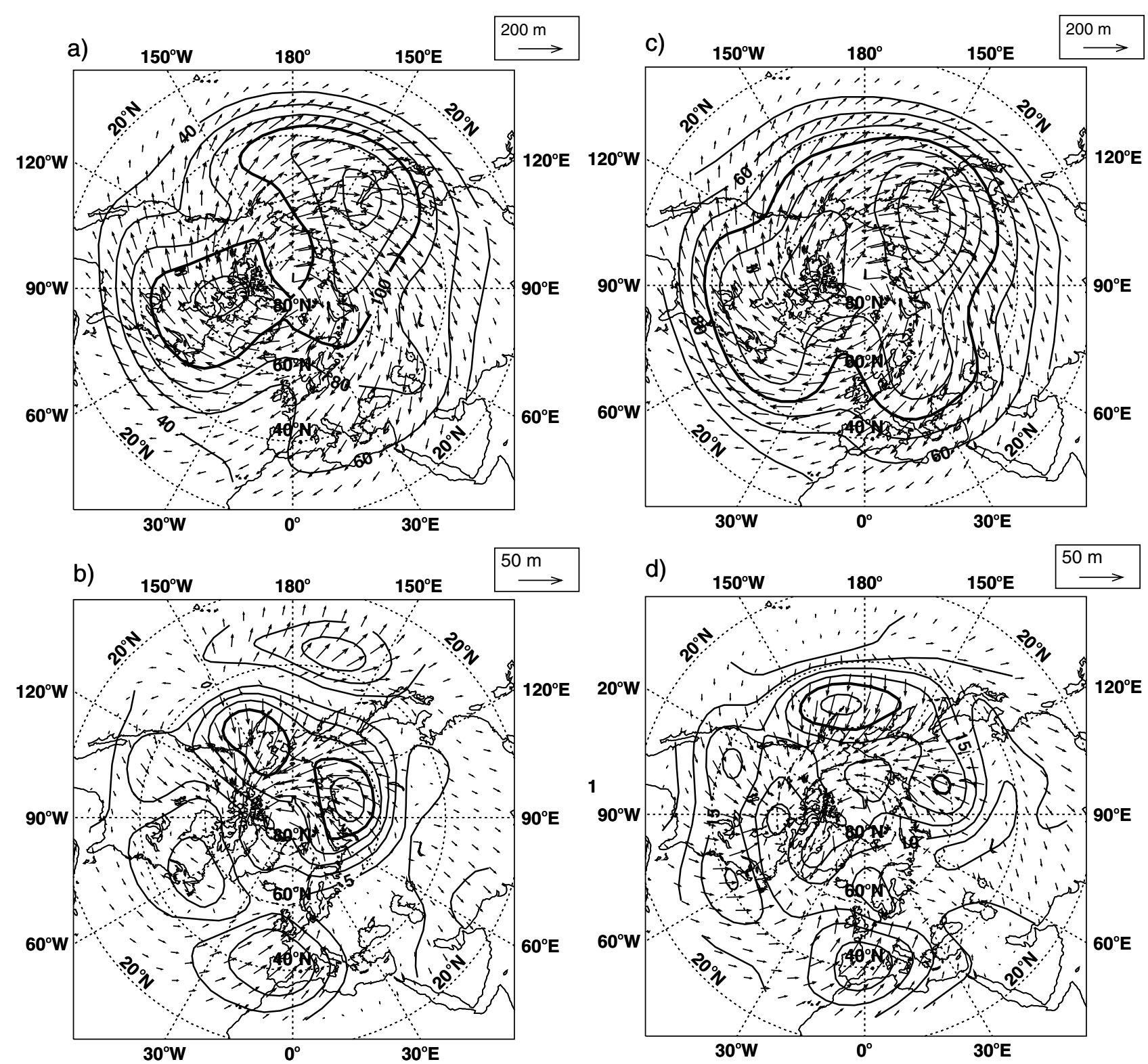

Figure 2. Annual component of the $500 \mathrm{hPa}$ geopotential height seasonal cycle for (a) the analyses and (c) ARPEGE. Plots (b) and (d) show the corresponding semiannual component. Contours represent the wave amplitude. The interval is $20 \mathrm{~m}$ for the annual wave and $5 \mathrm{~m}$ for the semiannual one. Vectors show a polar representation of the wave. Phase is measured starting from a tangent line to each latitude circle pointing to the right, corresponding to 1 January and then rotating anticlockwise. The maximum wave amplitude is indicated in the top right corner of each plot.

geopotential gradient shows the lowest values, and the stationary waves present a slightly different distribution mainly due to continental surface heating.

[19] Wintertime stationary waves are weaker for the model than for the analyses (Figure 1d). This implies an excess of zonality of the flow in the model, though the mean zonal flow is weaker than in the analyses (Figure 1c). Furthermore, the diffluence over the western part of the continents is underestimated. The northern section of the eastern Pacific ridge is missed by the model. These drawbacks are less evident in other seasons (not shown), though in any season the error in the time-mean structure would force the model to create higher-amplitude intraseasonal anomalies than needed to produce realistic blocking situations. A possible mechanism for explaining the sources of basic state errors is the barotropic feedback of the synoptic-scale perturbations over the mean flow [Hoskins et al., 1983]. Actually, as shown by Doblas-Reyes et al. [2001], the model displays excessively zonal storm tracks and underestimates the synopticscale propagating variance so that the feedback on the stationary waves is also underestimated. Moreover, differences in stationary wave features between the simulation and the analyses imply changes of the stationary wave activity fluxes [Reynolds et al., 19961 that may produce an inadequate forcing from and interaction with the low-frequency intraseasonal perturbations, as might be the case of blocking.

\subsection{Geopotential Height Seasonal Cycle}

[20] The geopotential height seasonal cycle provides a continuous estimate of the time-mean tropospheric seasonal evolu- 
tion regardless of the annual mean basic state. This is a sort of extra information to the stationary waves because the analysis is carried out in a grid point basis, and no zonal mean is involved. The two first harmonics of the seasonal cycle are analyzed here. Higher-order harmonics present smaller amplitude and will not be discussed here. The annual wave for the analyses, defined as the first harmonic in a typical 365-day seasonal cycle, is shown in Figure 2a, which offers information about the wave amplitude (both with contours and vector length) and phase (angles are measured from a tangent line to each latitude circle pointing to the right, corresponding to 1 January, and rotating anticlockwise). Two minima are observed over western North America and Europe, and two large areas of maximum amplitude are seen over both eastern Asia and North America. The wave amplitude is of the same order as the geopotential height low-frequency standard deviation with values decreasing southward. The wave antinode is attained in mid-July over all of the Northern Hemisphere (arrows pointing to $225^{\circ}$ ). The semiannual wave has less amplitude than the annual one (Figure 2b). Two different structures in the semiannual wave amplitude are found over the Pacific and Atlantic areas. Maxima are found at subtropical and polar latitudes over the Pacific and eastern Asia. The semiannual wave is in phase opposition over the north and south Pacific; the wave antinodes appear in February and July in both areas. A similar phase opposition is found over the Atlantic basin but among the western and eastern areas. As over the Pacific, wave maxima are found in February and July. In addition, the high amplitude of the semiannual wave over southern Europe and the subtropical North Pacific is a remarkable feature that is related to the important asymmetry of the seasonal cycle in those regions. This indicates that the role played by the semiannual wave in the seasonal cycle is highly dependent on the area.

[21] Van Loon et al. [1993] and Hurrell and van Loon [1994] have established a relationship between circulation changes and the seasonal cycle in the Southern Hemisphere. In a dynamical sense the region of maximum amplitude of the seasonal cycle is linked to a more important meridional migration during the year of the jet and the storm track. These structures migrate along with the stationary waves in the yearly summer compression and winter expansion processes in midlatitudes. A weakening or spatial shifting of the seasonal cycle amplitude might be related to changes in either intensity or location of midlatitude quasipermanent highs and troughs. Given the present spatial structure, the annual wave represents the meridional migration of the jets, their associated storm tracks, and the stationary waves, and the semiannual one is linked to some modifications of their regional features.

[22] Figure 2 also presents the two first harmonics for the model. Both maxima and minima locations and wave phase are satisfactorily simulated for the annual component. However, the wave amplitude is overestimated, the seasonal cycle being too strong in the model. The positions of the minima over the regions with maximum ILF variability are found to be in good agreement with the analyses. Concerning the semiannual wave, some important differences with the analyses are observed. The amplitude is slightly underestimated, the maximum over the subtropical Pacific is lacking, and the structure over the oceans is not correctly reproduced. The phase is well matched except for central Asia corresponding to a shift in the monsoon onset. Thus the model seems to better reproduce the annual component of the seasonal cycle than the semiannual one. This implies that some important regional drawbacks of the seasonal evolution in the model might be expected on the basis of the conceptual model explained above.

[23] As will be shown in this paper, the right simulation of the stationary waves seasonal evolution is as important to adequately represent the ILF perturbations as the correct representation of the

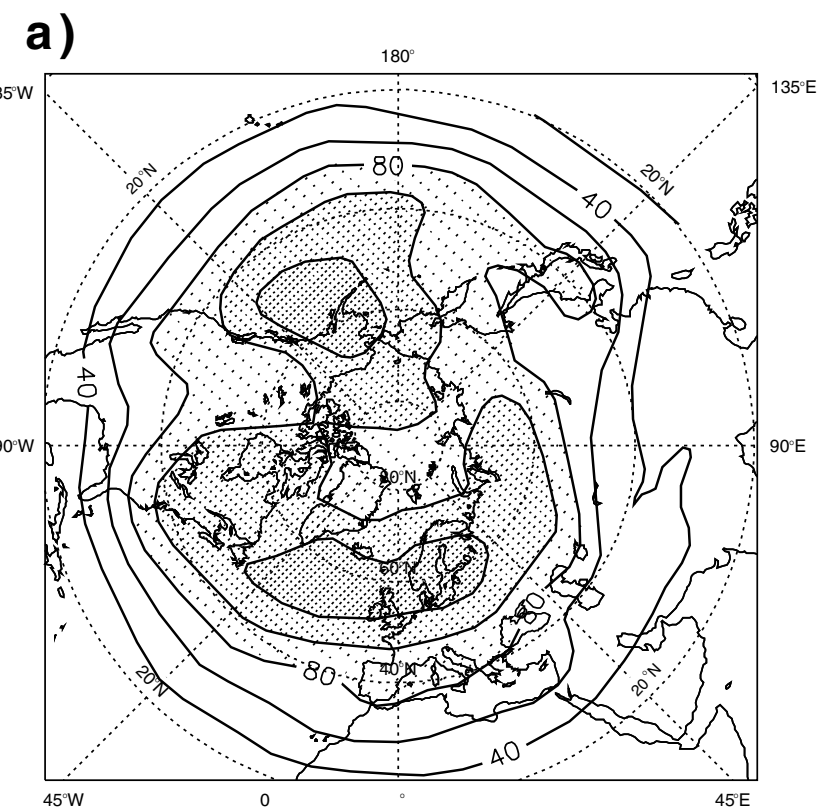

b)

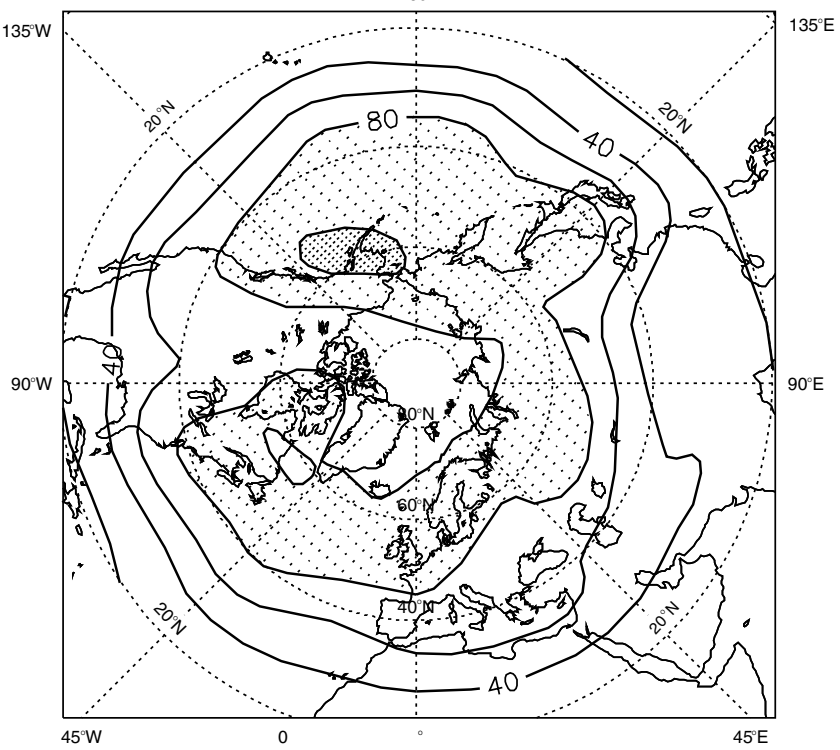

Figure 3. Standard deviation of the band-pass-filtered (5-45 days) $500-\mathrm{hPa}$ geopotential height in winter for (a) the analyses and (b) ARPEGE. Contour interval is $20 \mathrm{~m}$. Values above $80 \mathrm{~m}$ are shaded.

geographical distribution in a given season. This point was noticed in previous versions of the model in which important drawbacks were found in the geopotential height seasonal cycle. Nevertheless, that bias has been reduced in the present version, and a generally better simulation of the midlatitude circulation is found [DoblasReyes et al., 2001].

\subsection{Intraseasonal Variability}

[24] Transient disturbances are one of the main midlatitude circulation features. They are generally made up of synoptic-scale disturbances considered to be due to baroclinic instability; and by quasipersistent features whose timescale is larger than the life cycle of individual storms but shorter than the length of a season. The latter have time variations which produce the ILF variability. 
a)

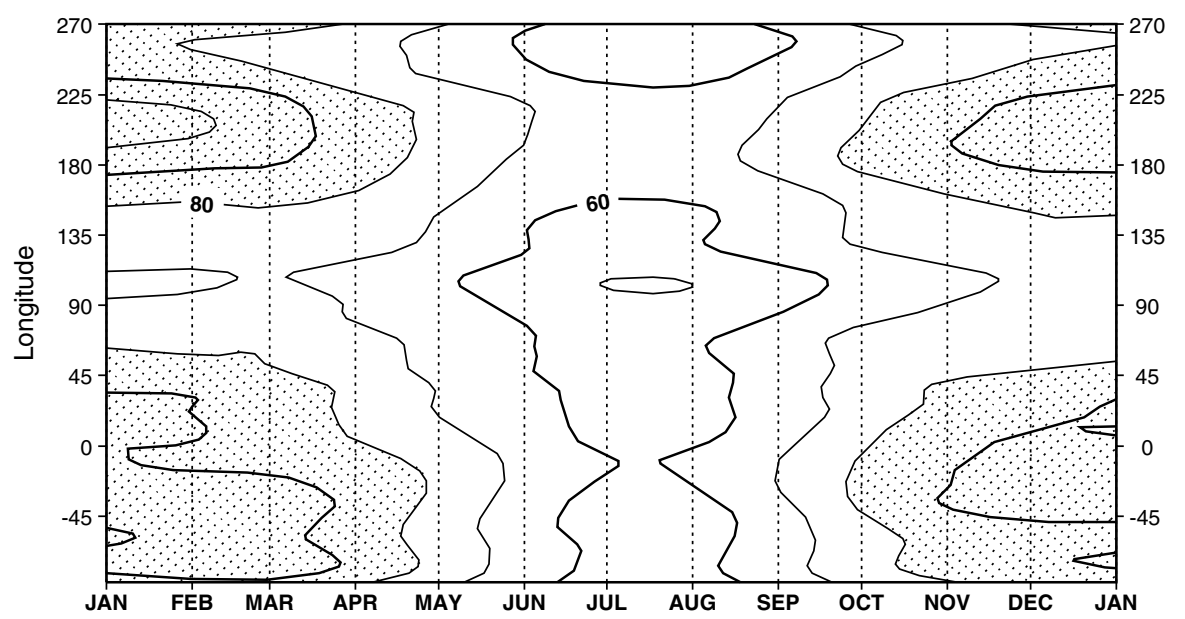

b)

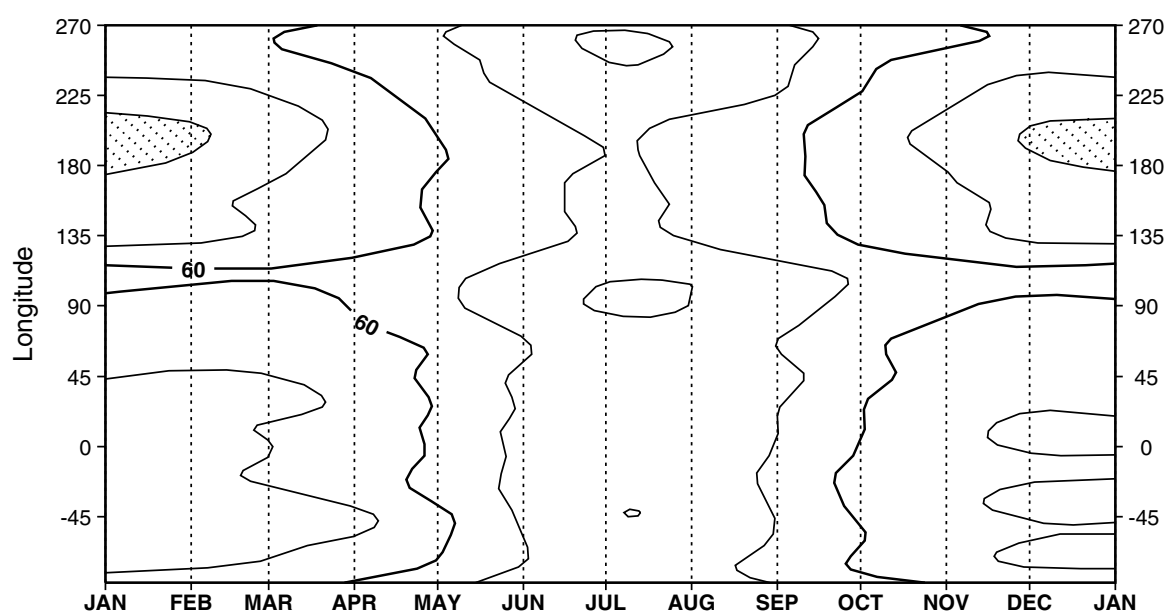

Figure 4. Monthly standard deviation of the band-pass-filtered 500-hPa geopotential height averaged over the Northern Hemisphere north of $20^{\circ} \mathrm{N}$ for (a) the analyses and (b) ARPEGE. The cosine of the latitude has been used as a weight in the averaging process. Contour interval is $10 \mathrm{~m}$. Values above $80 \mathrm{~m}$ are shaded.

Atmospheric blocking can be considered to belong to the second class, with a timescale in the range from $<1$ week up to slightly more than a month [Straus and Shukla, 1981]. The variability in such a band gives an idea of the day-to-day variations associated to blocking. A time-filtering procedure described by Doblas-Reyes and Déqué [1998] has been used here to extract the variability in the 5- to 45-day band. The cutoff frequencies have been chosen arbitrarily, though a set of similar frequency bands provided the same sort of results.

[25] Figure 3a presents the spatial distribution of the filtered standard deviation in winter for the analyses. The variance increases from south to north with a maximum in the band $50^{\circ}-70^{\circ} \mathrm{N}$. Two maxima are observed over the North Pacific and North Atlantic Oceans. Comparison with Figure 2 shows a relationship between the location of the minima of the annual component and the maxima of the ILF variance. The annual cycle minima location agrees well with the central position of the large ILF variance areas. This might imply that ILF variability extracts part of its energy from the annual atmospheric component. Figure 4a shows a Hovmoeller diagram of the monthly standard deviation of the filtered geopotential height averaged over the Northern Hemisphere north of $20^{\circ} \mathrm{N}$ for the analyses. A set of weights proportional to the cosine of the latitude has been applied in the averaging process. Two maxima are present during the extended winter (October to April): one over the North Pacific area and a longitudinally wider one over the North Atlantic. The lowest values are found in summer.

[26] The model does a reasonable job of simulating the broad features of the variability spatial distribution (Figure 3b). However, the simulation underestimates the standard deviation by around $20 \%$. The standard deviation seasonal cycle (Figure $4 \mathrm{~b}$ ) is underestimated accordingly. This means that the model has enough variance in the frequency band where atmospheric blocking generally appears, so that just some blocking frequency underestimation is expected. However, an important question to be answered is whether blocking in the model has the right amplitude and location to be detected with the same methodology developed for the analyses.

\section{Northern Hemisphere Blocking Features}

[27] Blocking features have been assessed using the two indices previously described. The results obtained with each index for the analyses and the model are described in this section. A comparison 

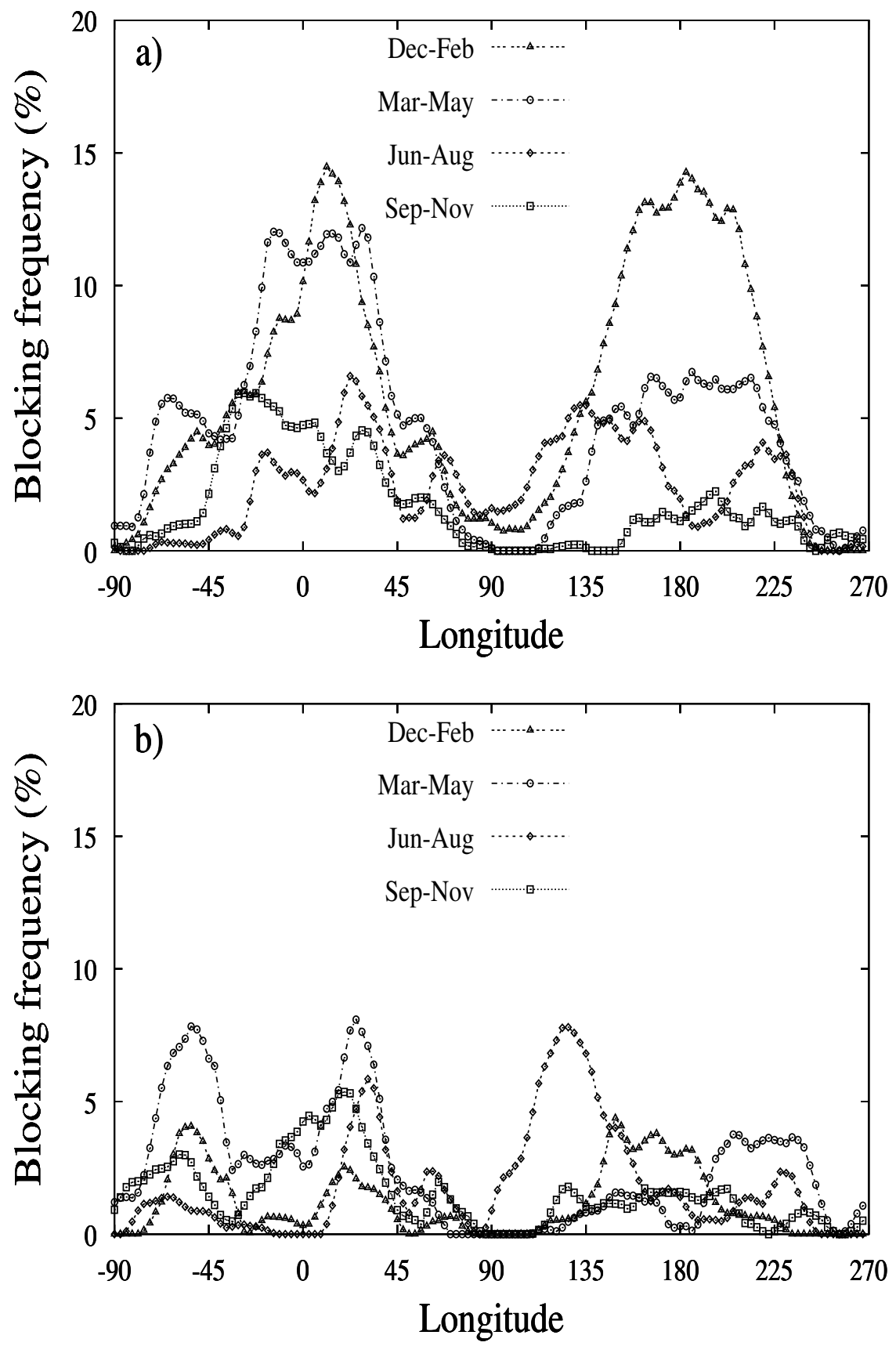

Figure 5. Mean seasonal blocking frequency computed for the raw data with the TM index against longitude for (a) the analyses and (b) ARPEGE.

between them along with a discussion of the differences will be presented in section 5 .

\subsection{TM Index}

[28] Figure 5a shows the seasonal mean blocking frequency over the Northern Hemisphere for the analyses. Blocking frequency is determined as the ratio of the number of blocked days at a given longitude to the total number of days of the season. Two main regions of maximum frequency are observed: one over the Pacific in winter and the second one over the Atlantic and Europe in winter and spring extending to Siberia, in agreement with the early works of Rex [1950] and Brezowski et al. [1951]. High values are also found in summer over the Pacific, as described by Lupo and Smith [1995]. Maximum frequencies attain values over $15 \%$. It must be noticed that the results presented here are not directly comparable with those from previous works because of the application of the time persistence criterion. However, the general shape of the distribution does not seem to change with our modifications to the index. Figure $5 \mathrm{~b}$ shows the mean seasonal blocking frequency for the model, which is strongly underestimated, as was also found for other climate models [e.g., Sausen and Ponater, 1990; Kaas and Branstator, 1993; Huth, 1994; D'Andrea et al., 1996]. Furthermore, a shift in time compared to the analyses is observed. The Euro-Atlantic region presents a maximum in spring, while a maximum appears in summer over the western Pacific region. 
a)

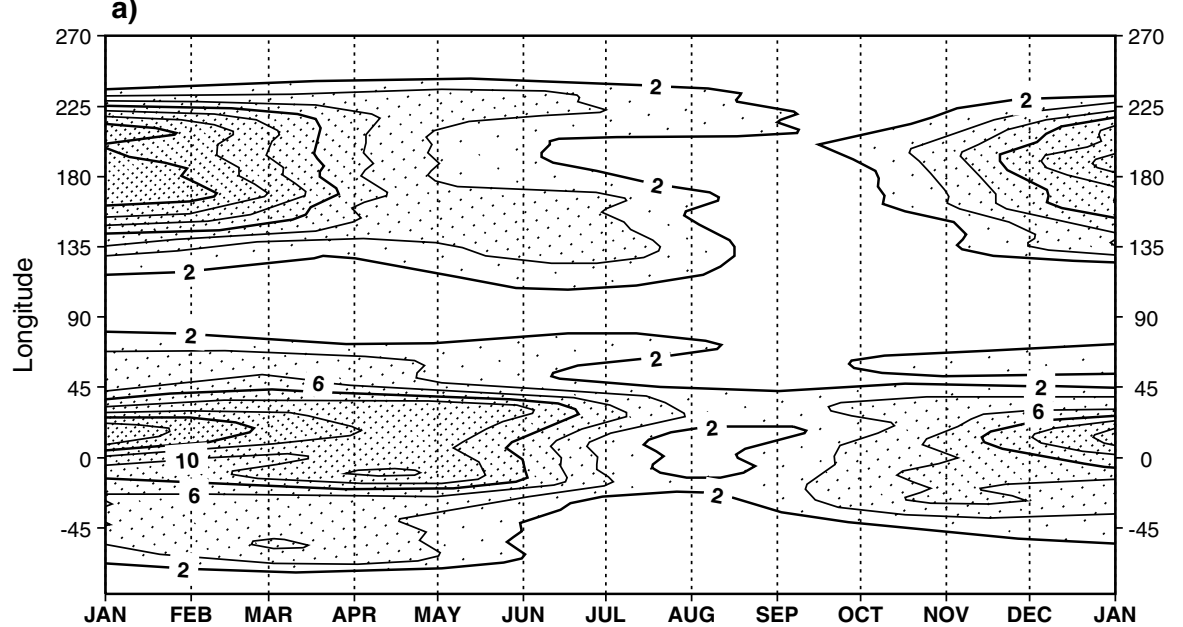

b)

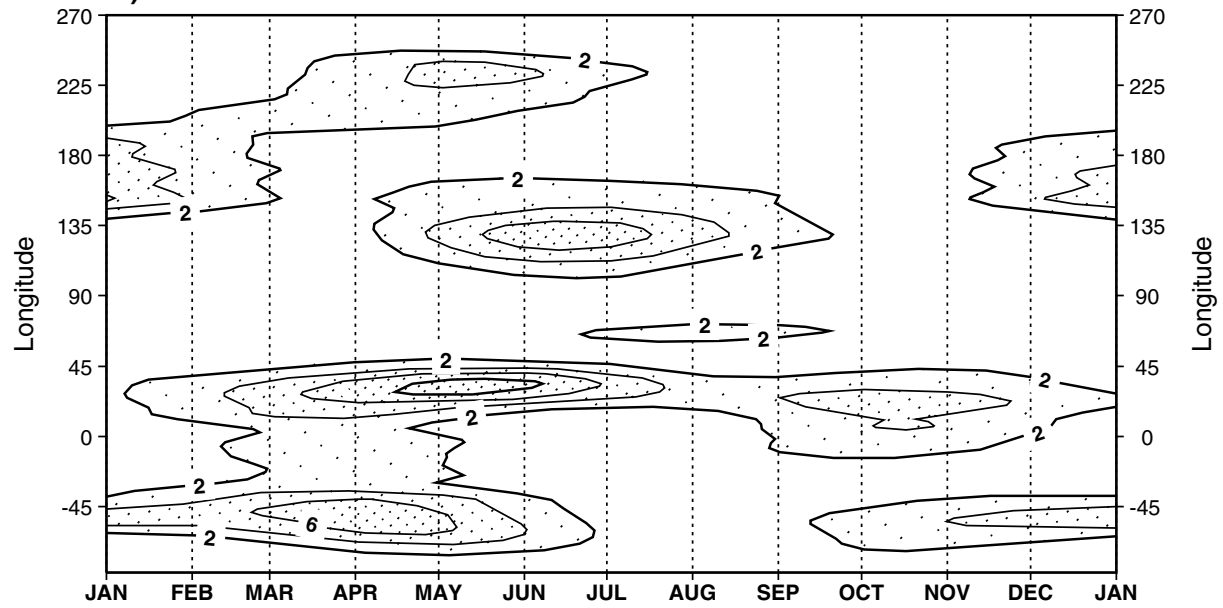

Figure 6. Mean monthly blocking frequency computed with the TM index on the raw data for (a) the analyses and (b) ARPEGE. Contour interval is $2 \%$. Areas above $2 \%$ are shaded.

The presence of this summer maximum is striking because a clear minimum of intraseasonal variability is observed at this time of the year (Figure $4 \mathrm{~b}$ ). This behavior is explained later on the basis of the different structure of the geopotential height seasonal cycle in the analyses and the model.

[29] Figure 6a shows a Hovmoeller plot of the mean monthly blocking frequency for the original analyses (raw data). There is a peak over the Euro-Atlantic sector in late winter lasting until early summer. The Pacific sector shows a peak in midwinter, dropping in April, and showing a secondary maximum with a split shape in early summer. The Euro-Atlantic late spring peak is simulated by the model but with a double shape (Figure $6 \mathrm{~b}$ ). The model's most remarkable features over this region are the low values in winter and the split-up of the maximum from winter to late spring. There are maxima in winter and summer over the Pacific, though shifted westward as in Figure 5. These preliminary results show a poor model performance with strong blocking frequency underestimation, which seems in some sense contradictory with the band-pass filtered standard deviation results.

[30] A possible reason for the model to show such a poor blocking frequency performance might be found in the fact of the TM index not taking into account the geopotential height seasonal cycle. To assess the impact of the geopotential height seasonal cycle on the blocking frequency assessment, the three first harmonics of the seasonal cycle have been removed from the raw data. The idea is to remove the bias introduced by the geopotential height seasonal cycle. The new dataset will be hereinafter referred to as seasonal cycle bias-free data. The removal of the seasonal cycle also accounts for the lack of seasonal variation in the index parameters. This is an important aspect when trying to automatically detect blocking events. The parameters of the blocking index have been seasonally changed, for instance, in the blocking criteria of Shukla and Mo [1983] and Knox and Hay [1984]. As a result of removing the geopotential height seasonal cycle, the blocking frequency seasonal evolution changes when the seasonal cycle is removed. Figure $7 \mathrm{a}$ shows that the summer peak over the Pacific has disappeared for the analyses. This picture is much in agreement with the band-pass filtered standard deviation shown in Figure $4 \mathrm{a}$, although regional maxima of blocking frequency appear in a narrower band. Values are still higher over the Euro-Atlantic region than over the Pacific. A clearer seasonal evolution of the monthly blocking frequency for the analyses is also evidenced with maxima in late fall, winter, and early spring. Furthermore, the agreement among analyses and model blocking frequency seasonal evolution is higher when the geopotential height seasonal cycle is removed, as may be appreciated comparing Figures $7 \mathrm{a}$ and $7 \mathrm{~b}$. When comparing the band-pass-filtered standard deviation (Figure 4) 
a)

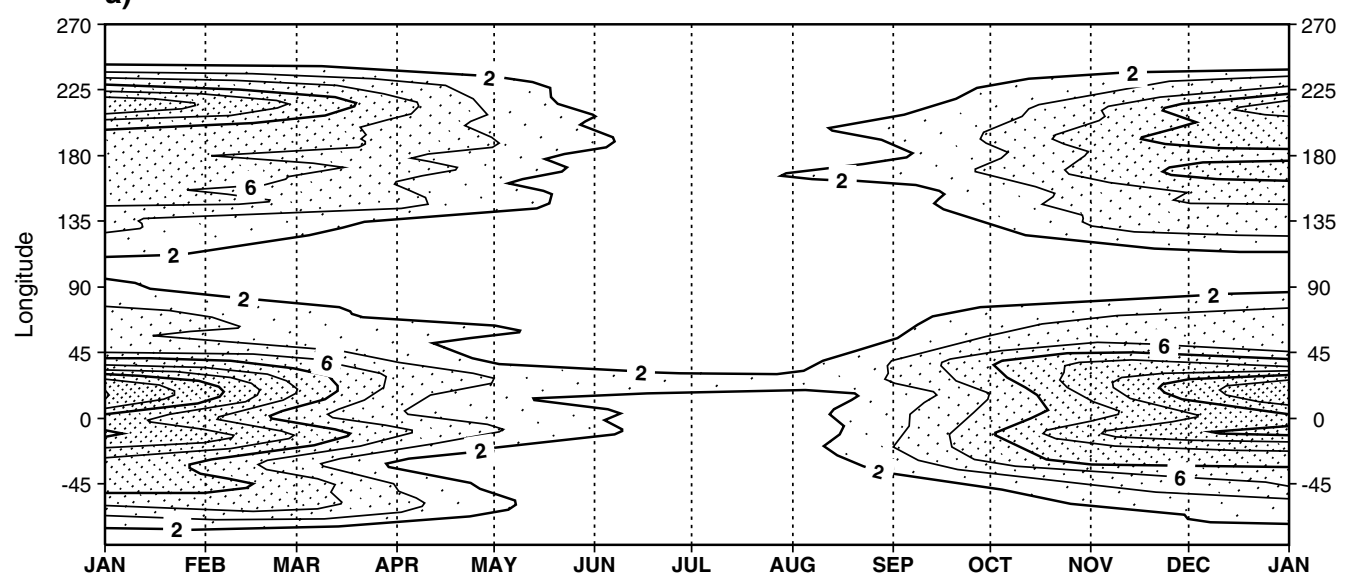

b)

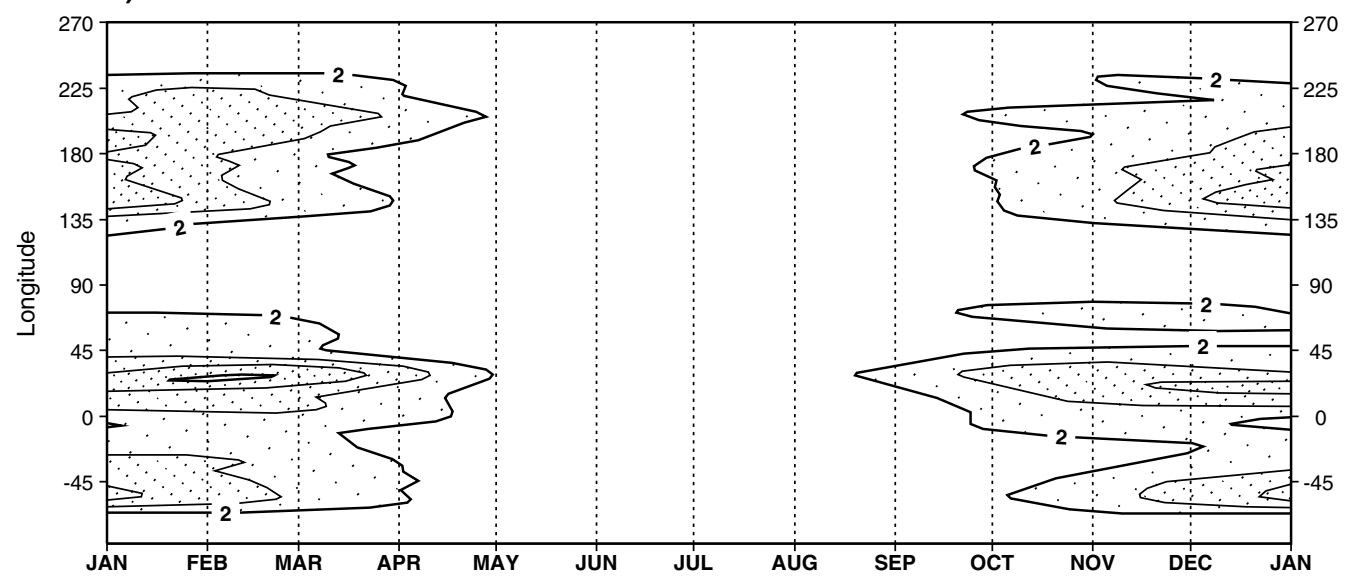

c)

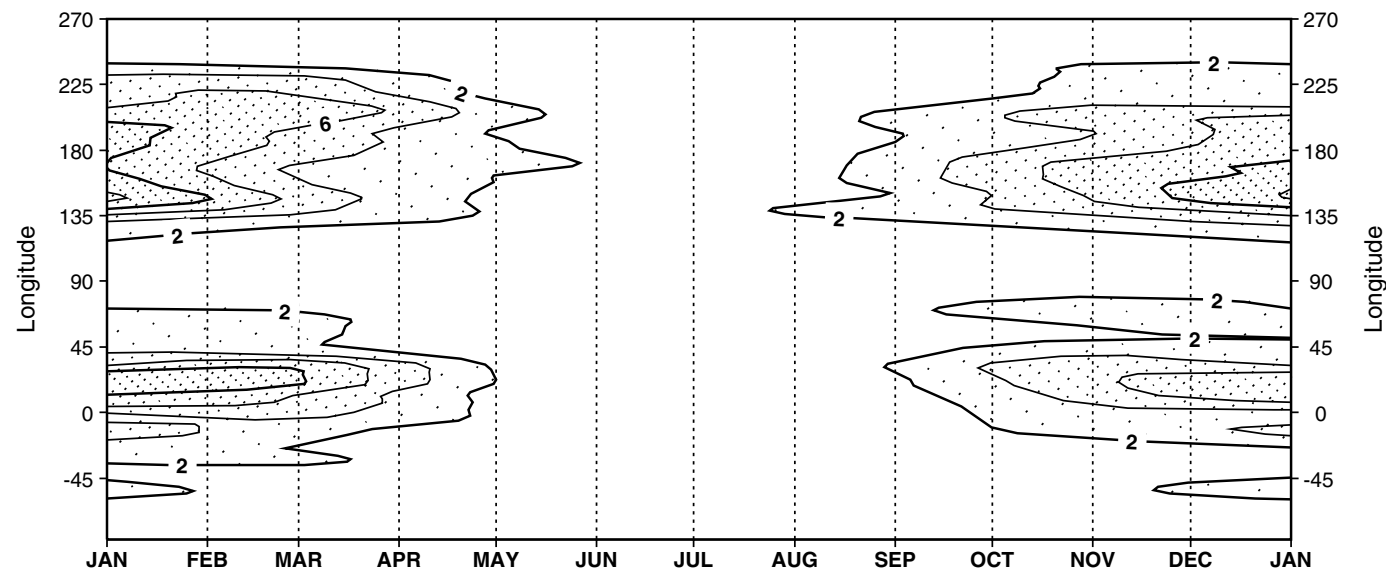

Figure 7. Mean monthly blocking frequency computed with the TM index on the seasonal cycle bias-free data for (a) the analyses and (b) ARPEGE. (c) Values obtained with model data for which bias of time-mean state has been removed. Contour interval is $2 \%$. Areas above $2 \%$ are shaded.

with the mean monthly blocking frequency (Figure 7), the strongest difference between the model and analyses consists in a higher underestimation of the blocking frequency than of the band-pass standard deviation. A possible explanation for this disagreement might be found in the effect of the timemean model bias.

[31] Miyakoda and Sirutis [1990] pointed out the great effect of the time-mean state on the blocking frequency. Sausen and
Ponater [1990] showed that a dynamical correction of the systematic error improved the blocking simulation. A similar result was found by Kaas and Branstator [1993]. Owing to its definition, the results of the TM index may depend strongly on the set of latitudes chosen. Thus it is not unreasonable to consider that when the model is affected by some time-mean bias, this might in turn affect adversely the applicability of the blocking index to a climate simulation, as already noted by 
Table 1a. Mean Number of Blocked Days and Mean Duration of Blocking Episodes Detected for Each Season With the TM Index on the Raw Data of Analyses ${ }^{\mathrm{a}}$

\begin{tabular}{lccccccc}
\hline & \multicolumn{3}{c}{ Blocked Episodes, days } & & \multicolumn{3}{c}{ Duration, days } \\
\cline { 2 - 5 } \cline { 6 - 8 } & ATL & PAC & SIB & & ATL & PAC & SIB \\
\hline Winter & 33 & 35 & 5 & & 10 & 11 & 5 \\
Spring & 45 & 16 & 6 & & 11 & 8 & 7 \\
Summer & 12 & 13 & 3 & & 9 & 8 & 7 \\
Fall & 26 & 5 & 2 & & 10 & 8 & 9 \\
\hline
\end{tabular}

${ }^{a}$ ATL, Atlantic; PAC, Pacific; SIB, Siberian.

Sausen et al. [1995] and Tibaldi et al. [1997] for the ECHAM model. A simple way of removing part of the blocking frequency bias owing to the difference in the time-mean states (and, partly, in stationary waves) consists in subtracting an estimate of the model bias to each daily field from the simulation, that is,

$$
Z_{\text {model }}(\phi, \lambda)=Z_{\text {model }}(\phi, \lambda)+\overline{Z_{\text {analysis }}(\phi, \lambda)}-\overline{Z_{\text {model }}(\phi, \lambda)},
$$

where the overbar means time averaging over a season. The TM index has been newly applied to these data. The mean monthly blocking frequency can be observed in Figure 7c. The model improves by increasing the frequency mainly in the Pacific sector although still underestimates the analyses values. Figure $7 \mathrm{c}$ shows that blocking underestimation using the TM index is not just reflecting a lack of model variability but also the impact of some biases in the basic state of the model that should be analyzed separately.

[32] Other blocking features have also been analyzed. The number of blocked days and the mean duration of the episodes for three regions are shown in Tables $1 \mathrm{a}$ and $1 \mathrm{~b}$. The mean duration agrees with the values found in other studies [Lupo and Smith, 1995; Corti et al., 1997]. In general, there are a higher number of blocked days over the Euro-Atlantic than over the Pacific region. These differences are sensibly reduced when a Pacific wider area $\left(100^{\circ} \mathrm{E}-100^{\circ} \mathrm{W}\right)$ is considered. A high number of blocked days over the Euro-Atlantic in spring for the raw data are evidenced both in the analyses and the model as by Tibaldi et al. [1994]. This feature is not observed in the seasonal cycle bias-free data; the seasonal evolution for the Euro-Atlantic and Pacific blocking present a higher agreement (Table 2a). The mean duration of the episodes does not seem strongly affected by this modification. The Siberian blocking shows also a clear seasonal evolution with a minimum in summer. The model underestimates, as expected, both the number of blocked days and the mean duration of the episodes (Tables $1 \mathrm{~b}$ and $2 \mathrm{~b}$ ). However, the distribution throughout the year is more realistic with the seasonal cycle bias-free data. When the time-mean state bias is also removed, the Pacific blocking features show the main improvement (Table 2c).

Table 1b. Mean Number of Blocked Days and Mean Duration of Blocking Episodes Detected for Each Season With the TM Index on the Raw Data of ARPEGE ${ }^{a}$

\begin{tabular}{lccccccc}
\hline & \multicolumn{3}{c}{ Blocked } & Episodes, days & & \multicolumn{3}{c}{ Duration, days } \\
\cline { 2 - 5 } \cline { 6 - 8 } & ATL & PAC & SIB & & ATL & PAC & SIB \\
\hline Winter & 10 & 7 & 1 & & 9 & 9 & 7 \\
Spring & 27 & 7 & 1 & & 10 & 9 & 6 \\
Summer & 6 & 4 & 2 & & 8 & 7 & 6 \\
Fall & 15 & 5 & 1 & & 9 & 7 & 6 \\
\hline
\end{tabular}

${ }^{\mathrm{a}}$ ATL, Atlantic; PAC, Pacific; SIB, Siberian.
Table 2a. Mean Number of Blocked Days and Mean Duration of Blocking Episodes Detected for Each Season With the TM Index on the Seasonal Cycle Bias-Free Data of the Analyses ${ }^{\mathrm{a}}$

\begin{tabular}{llllllll}
\hline & \multicolumn{3}{c}{ Blocked Episodes, days } & & \multicolumn{3}{c}{ Duration, days } \\
\cline { 2 - 5 } \cline { 6 - 8 } & ATL & PAC & SIB & & ATL & PAC & SIB \\
\hline Winter & 42 & 26 & 6 & & 12 & 9 & 8 \\
Spring & 25 & 18 & 5 & & 8 & 9 & 7 \\
Summer & 6 & 6 & 0 & & 7 & 7 & 0 \\
Fall & 35 & 14 & 7 & & 11 & 7 & 8 \\
\hline
\end{tabular}

${ }^{a}$ ATL, Atlantic; PAC, Pacific; SIB, Siberian.

[33] Figure 8 illustrates the winter blocking signature pattern obtained by subtracting the composite field of all nonblocked days from the composite field of all blocked days over a given region. For the sake of simplicity, the signatures for the blocking situations detected on the seasonal cycle biasfree data will be presented. These maps can be regarded as the mean synoptic structures of the blocked regime and show the shape, extension, and intensity of the mean blocking structure [Vautard, 1990]. The model signatures obtained when the time-mean bias is removed are more similar in shape and location to the ones of the analyses than the signatures from the raw and the seasonal cycle bias-free data, so that we will restrict the description to the former. This fact shows again the strong importance of simulating a correct time-mean state as, when just applying a linear correction, the model blocking features seem more realistic. For the analyses the Euro-Atlantic sector shows localized signatures all year round. The dipole is centered close to the Greenwich meridian in winter (Figure 8a) and spring, slightly displaced eastward in summer, and westward in autumn. The model shows (Figure 8d) the dipole shifted eastward. This difference in the Euro-Atlantic signature in the analyses and the model may be analyzed by assessing separately the WA and EA blocking signatures. This kind of analysis has been already performed by other authors and agrees well with the results from Michelangeli et al. [1995] that show two different blocking-like weather types over the Euro-Atlantic region: the "Greenland anticyclone" and the "European blocking." The WA signature (Figure 9a) presents a strong positive anomaly close to $40^{\circ} \mathrm{W}$ north of a wide negative anomaly spanning all of the Atlantic Ocean and Europe. The EA signature (Figure 9c) is more spatially confined (except in summer) with a weaker dipole located around the Greenwich meridian. The model shifts westward the minimum of the WA signature (Figure 9b). However, the EA signature (Figure 9d) is shifted eastward around $15^{\circ}$. This would explain the eastward shifting of the Euro-Atlantic blocking signature in the model.

[34] The Siberian signature (Figure 8b) corresponds to a wave number 3 wave train similar to the Eurasian pattern type 1 [Barnston and Livezey, 1987] teleconnection pattern. This phase corresponds to an intense zonal flow over the Atlantic and a ridge

Table 2b. Mean Number of Blocked Days and Mean Duration of Blocking Episodes Detected for Each Season With the TM Index on the Seasonal Cycle Bias-Free Data of ARPEGE ${ }^{a}$

\begin{tabular}{lllllcccc}
\hline & \multicolumn{3}{c}{ Blocked Episodes, days } & & \multicolumn{3}{c}{ Duration, days } \\
\cline { 2 - 3 } \cline { 6 - 8 } & ATL & PAC & SIB & & ATL & PAC & SIB \\
\hline Winter & 25 & 12 & 4 & & 9 & 9 & 8 \\
Spring & 12 & 14 & 1 & & 8 & 8 & 7 \\
Summer & 0 & 1 & 0 & & 0 & 6 & 0 \\
Fall & 13 & 7 & 3 & & 8 & 8 & 6 \\
\hline
\end{tabular}

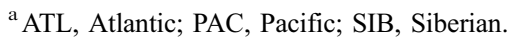


Table 2c. Mean Number of Blocked Days and Mean Duration of Blocking Episodes Detected for Each Season With the TM Index on the Seasonal Cycle Bias-Free Data of ARPEGE, For Which the Time-Mean State Bias Has Been Removed ${ }^{\mathrm{a}}$

\begin{tabular}{lccccccc}
\hline & \multicolumn{3}{c}{ Blocked Episodes, days } & & \multicolumn{3}{c}{ Duration, days } \\
\cline { 2 - 5 } \cline { 6 - 8 } & ATL & PAC & SIB & & ATL & PAC & SIB \\
\hline Winter & 21 & 17 & 4 & & 8 & 9 & 9 \\
Spring & 11 & 9 & 1 & & 9 & 9 & 9 \\
Summer & 0 & 2 & 0 & & 0 & 7 & 0 \\
Fall & 12 & 13 & 3 & & 8 & 9 & 7 \\
\hline
\end{tabular}

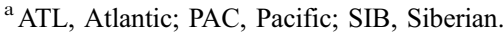

over eastern Europe. A similar signature is found in the model (Figure 8e), although shifted southward.

[35] Both the analyses (Figure 8c) and the model (Figure 8f) are characterized over the Pacific region by a localized signature in winter, spring, and autumn. The dipole is located close to $160^{\circ} \mathrm{W}$. The analyses show a longitudinal extension of the maximum in winter. The Pacific signature resembles the Alaskan teleconnection pattern [Renwick and Wallace, 1998], in contradiction with D'Andrea et al. [1998], who find a Pacific North American teleconnection (PNA)-like signature. The model signature is very similar to the analyses both in location and intensity.

\subsection{SKS Index}

[36] The geographical distribution of the SKS winter blocking frequency for the analyses is displayed in Figure 10a. A threefold structure is observed, which is present all the year round except in summer [Sausen et al., 1995] when the estimated blocking activity vanishes, in contrast with Shukla and Mo's [1983] results. Other authors found the same threefold structure, though shifted southward [Dole and Gordon, 1983]. This discrepancy could be explained by the correction of the height anomalies by the latitude they carried out. These three maxima are located over the northeastern Pacific, northern Atlantic between Greenland and Iceland, and western Siberia. Their longitude distribution is in agreement with the corresponding band-pass-filtered variability maxima (Figure 4) and with the results of Shukla and Mo [1983]. The Pacific region shows the higher values in winter and spring and the EuroAtlantic in fall (not shown). The model underestimates considerably the blocking frequency (Figure 10b) when the reference parameters of the index are used. This strong underestimation of the blocking frequency may imply that the SKS frequency estimations for the model might be artificially reduced. A possible reason could be related to the arbitrarily high parameters used for the SKS index definition. In fact, the blocking frequency increases for both analyses and model output when the reference parameters for the SKS index are relaxed toward lower values. Actually, when the model-specific parameters for $Z_{1}$ and $Z_{2}$ are used (Figure 10c), the blocking underestimation is strongly reduced over the Pacific, though it still persists over the Euro-Atlantic area.

[37] A longitudinal blocking frequency distribution can be estimated using the bidimensional fields of detected blocking episodes as input. We counted the number of days with a blocking event at a certain longitude and at any latitude north of $20^{\circ} \mathrm{N}$ and divided by the total number of days. Estimations will allow for the comparison with the TM index results. The mean monthly blocking frequency against longitude for the analyses is shown in Figure 11a. Maximum frequencies attain values close to $15 \%$ in the analyses and $8 \%$ in the model. Two of the main regions of blocking activity are also found in this plot. A maximum over the western Euro-Atlantic region is observed in winter for the analyses. This maximum appears in late autumn and decays in early spring. There is a secondary maximum over the eastern Atlantic and the Siberian region in winter. The maximum in the Pacific region is located around $150^{\circ} \mathrm{W}$. This peak begins in late autumn and disappears in late spring. When comparing these results with the ones shown in Figure 7, the only important difference that may be found is the westward shift of the Euro-Atlantic maximum. The model underestimates considerably these maxima when the reference parameters of the index are used (Figure 11b), especially in the Euro-Atlantic area. As for the TM index results, the underestimation is far greater than the one found for the band-pass intraseasonal variability. However, Figure $11 \mathrm{c}$ shows that the blocking frequency estimates for the model improve when the model-specific parameters are used, with the Pacific region being quite realistic (except for a westward drift during winter) and the Euro-Atlantic area underestimating in autumn and early winter. In the following, just the results obtained with the model-specific parameters will be presented.

[38] Tables $3 \mathrm{a}$ and $3 \mathrm{~b}$ shows the mean number of blocking days and the mean duration of the blocking episodes over the same three regions considered for the TM index. The SKS index detects, in general, a smaller number of blocked days than the TM index all over the year, as could be seen comparing Figures 7 and 11. The mean duration of the episodes also tends to be shorter. The model underestimation of the number of blocking days over the Euro-Atlantic persists (except in spring) when using the model-specific parameters (Table 3b), blocking features over the Pacific region being strikingly similar to the analyses.

[39] Figure 12 displays the signatures of the winter blocking episodes detected with the SKS index. These plots show stronger patterns than those of Figure 9. This is mainly due to the lower number of maps averaged in the blocking ensemble. The Euro-Atlantic region shows localized signatures in winter, spring, and fall with the positive area located over southeast Greenland and the minimum over the Iberian Peninsula (Figure 12a). The EA and WA signatures are now less distinct than with the TM index (not shown). The positive area of the EA dipole is placed close to $20^{\circ} \mathrm{W}$, WA being the one close to $40^{\circ} \mathrm{W}$; both negative areas are equally located over the Iberian Peninsula. The model shows localized signatures over the Euro-Atlantic region with a slight southward shift of the dipole (Figure 12d). In this case, the eastward shift of the dipole shown in Figure 8d is corrected. The Siberian region shows significant signatures only in winter (Figure 12b). They look quite similar to the ones detected with the TM index (Figure 8b), though the model shifts the minimum anomaly eastward (Figure 12e). Localized signatures are found in winter, spring, and fall in the Pacific region, the amplitude being higher in winter (Figure 12c). The pattern is again very similar to that of Figure $8 \mathrm{c}$. The model matches this pattern (Figure 12f) with a dipole shifted slightly westward, in agreement with previous results.

\section{Differences Between Indices}

[40] An interesting result when comparing the blocking features obtained with both indices is the increased agreement of the blocking frequency seasonal evolution (compare Figures $7 \mathrm{a}$ and 11a) when removing the geopotential height seasonal cycle from the data before applying the TM index. This higher agreement is also found with the standard deviation of the band-pass- filtered data for which the seasonal cycle is always removed. This fact puts forward the importance of analyzing separately the different timescales involved in the validation of climate simulations and, in particular, in the assessment of blocking. In spite of that, a clear difference in the mean monthly blocking frequency estimated by each index still 
a)

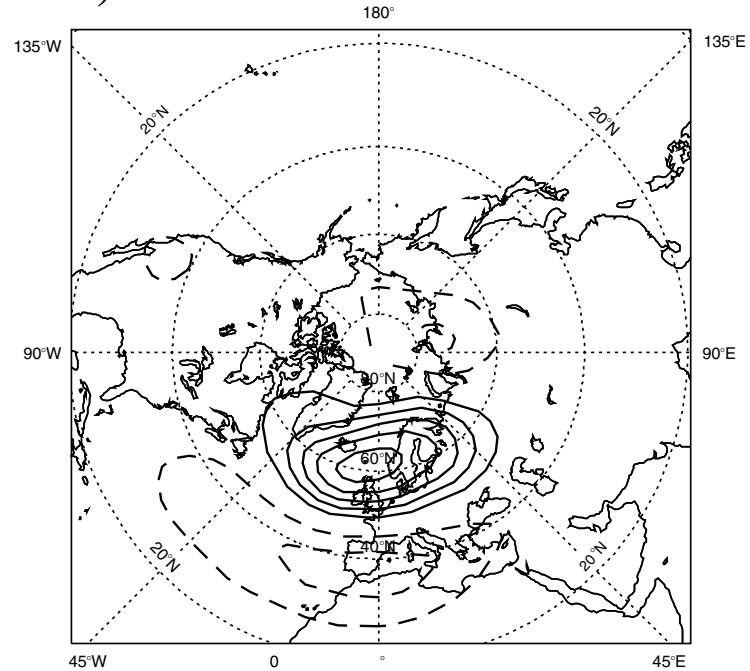

b)

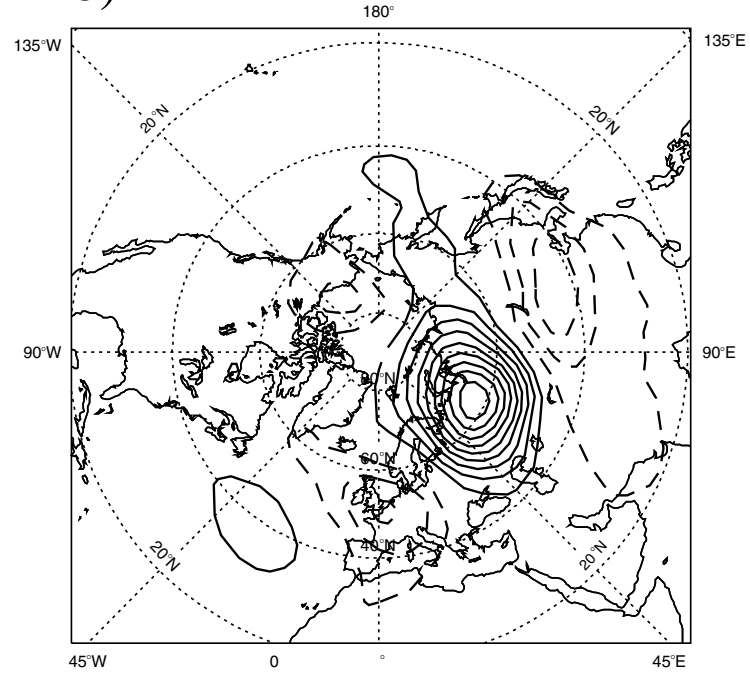

c)

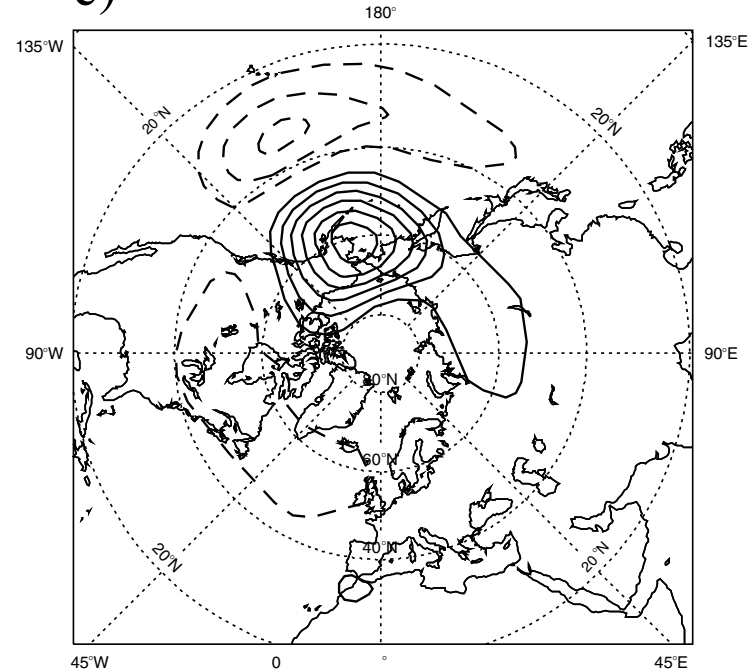

d)

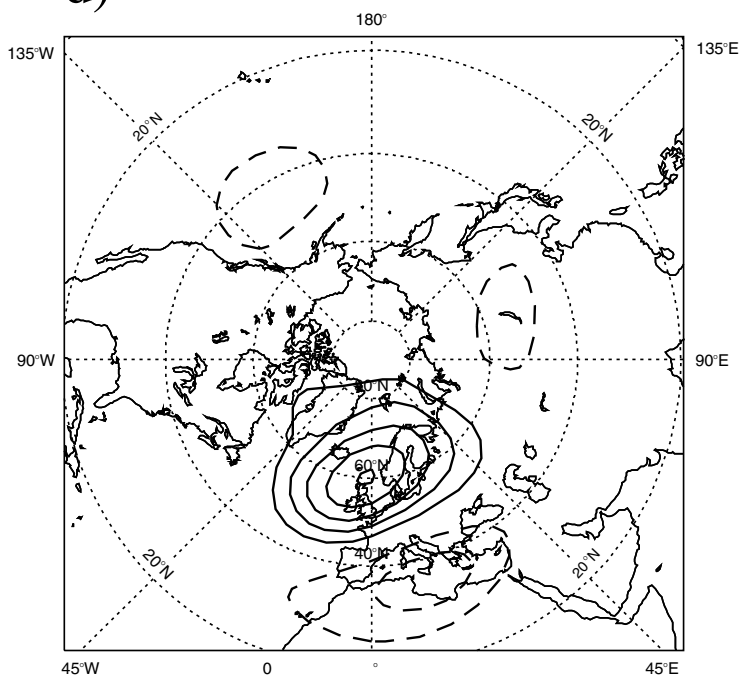

e)

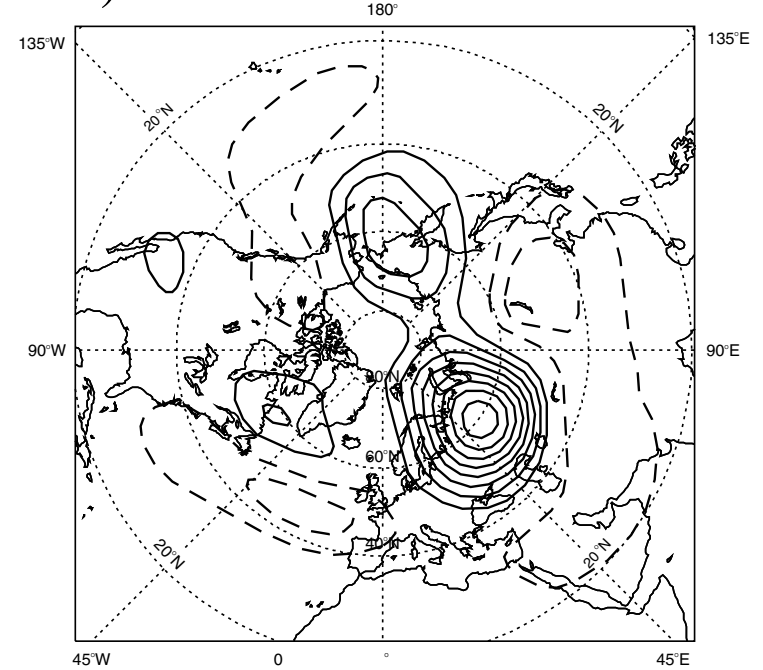

f)

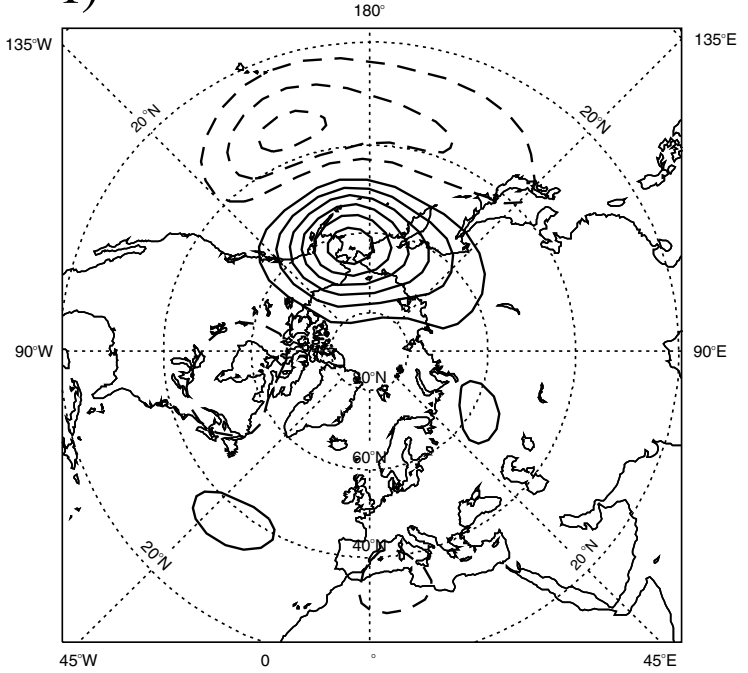

Figure 8. Difference between mean fields of $500 \mathrm{hPa}$ geopotential height in the sets of blocked and nonblocked days (blocking signature) detected in the analyses with the TM index for (a) the Euro-Atlantic blocking, (b) Siberian blocking, and (c) Pacific blocking in winter. Plots (d), (e), and (f) display results for the corresponding three blocking sectors in the model. Contour interval is $30 \mathrm{~m}$. The zero isoline has been skipped. 
a)

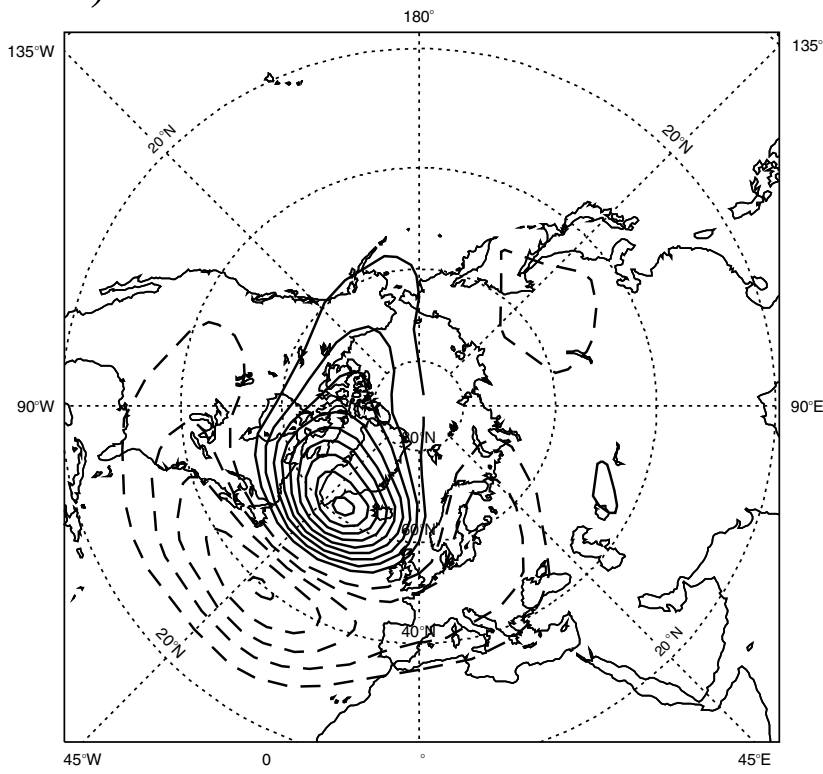

c)

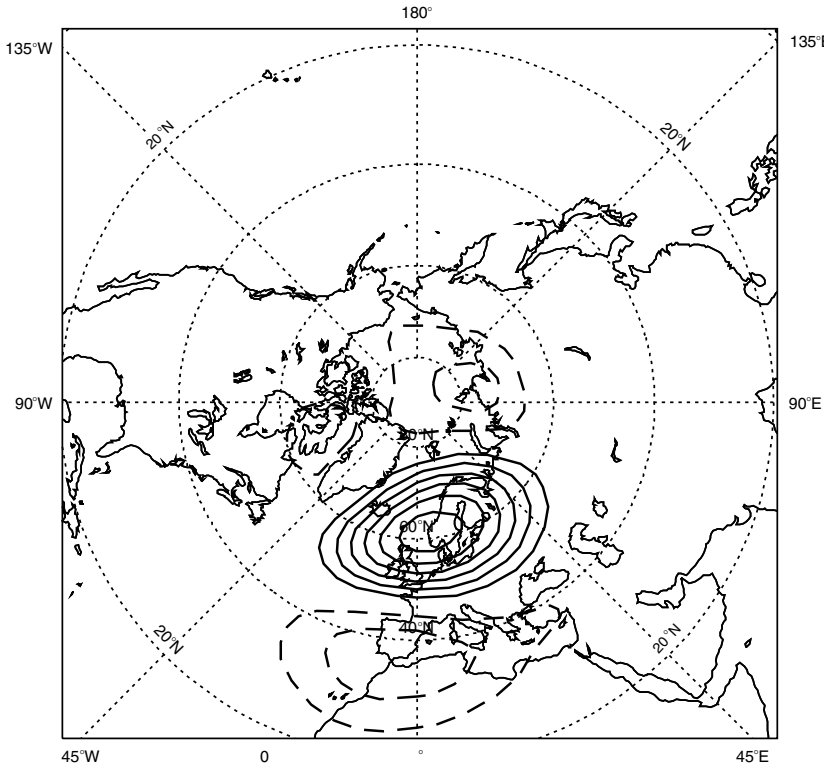

b)

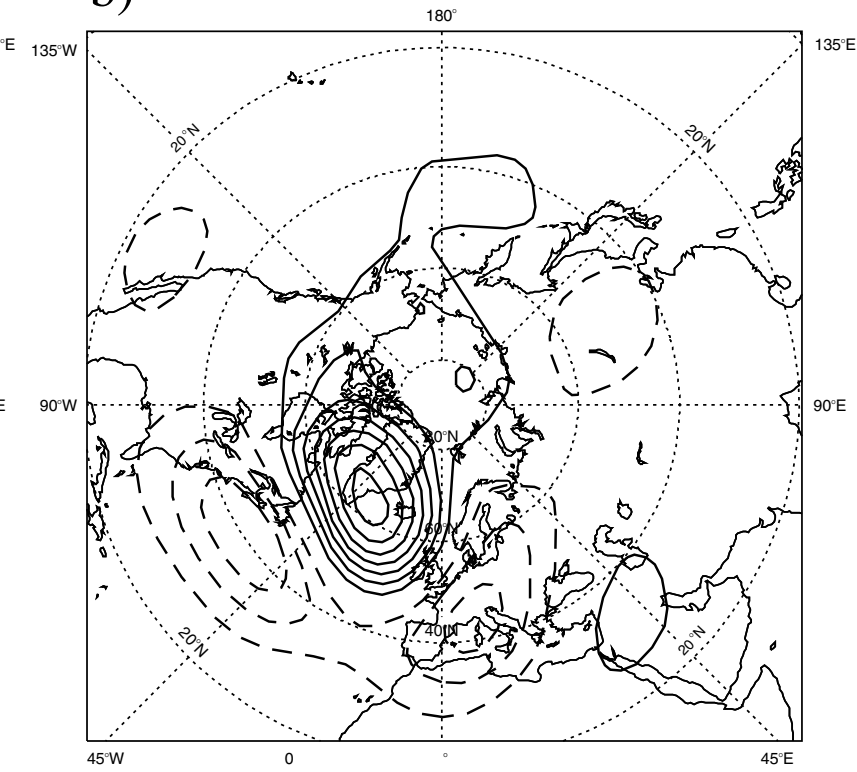

d)

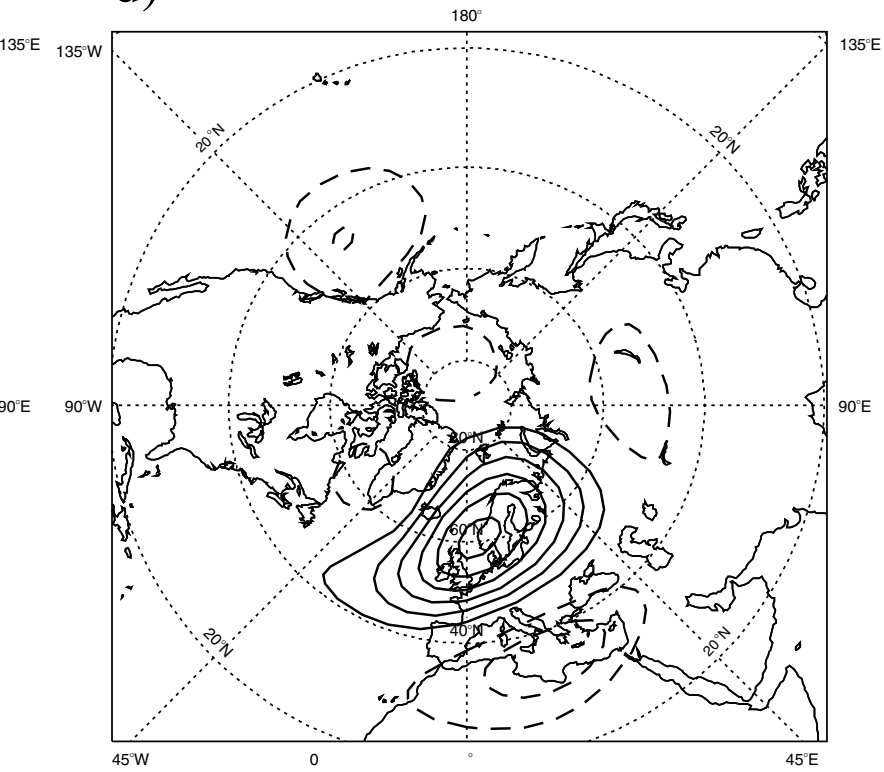

Figure 9. Wintertime blocking signatures detected with the TM index for the Western Atlantic (WA) area for (a) the analyses and (b) ARPEGE and for the Eastern Atlantic (EA) area for (c) the analyses and (d) ARPEGE. The patterns correspond to the seasonal cycle bias-free data. The time-mean bias correction has been applied to the model data. Contour interval is $30 \mathrm{~m}$. The zero isoline has been skipped.

comes out. The SKS index estimates of blocking frequency are lower for both the analyses and the model than the TM index estimates over the Euro-Atlantic area and higher over the Pacific. Other authors have already shown that blocking has different dynamical and geographical features in these two regions. For instance, the differences in the Pacific region blocking frequency between both performance indices reflect an intrinsic difficulty in unambiguously defining Pacific blocking. A possible explanation might be found in the different incidence of dipolar blocking structures versus omega-type structures in the estimated frequencies. The first type is much easier to diagnose with the TM index because the strength of the reverse flow inside the dipole tends to be much stronger than that occurring to the south of an omega block [Tibaldi et al., 1995]. Dipolar blocking seems to be, in fact, more common in the Euro-Atlantic sector, while omega-type blocks tend to occur more often in the Pacific. Actually, most blocking events in the Northern Hemisphere involve an intensification of two or more waves simultaneously, and the involved waves are different depending upon whether a block is over the Euro-Atlantic or the Pacific region [Austin, 1980; Trenberth and Mo, 1985. Thus the regional differences in blocking 
a)

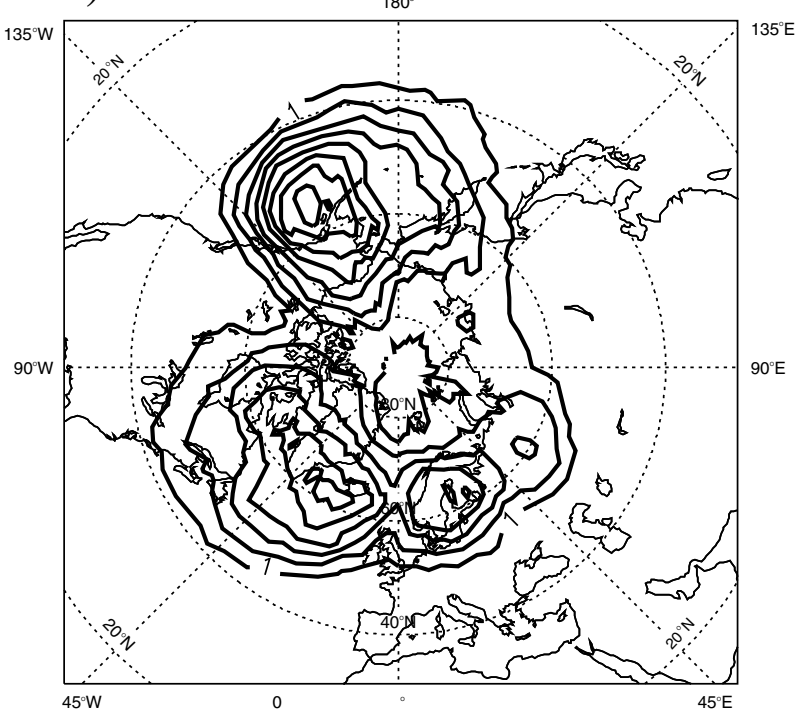

b)

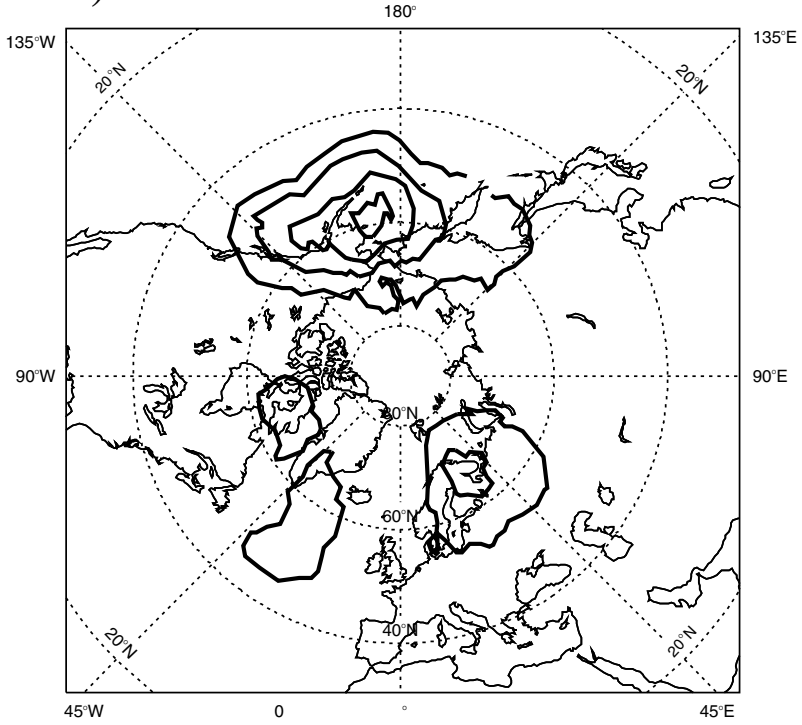

c)

$180^{\circ}$

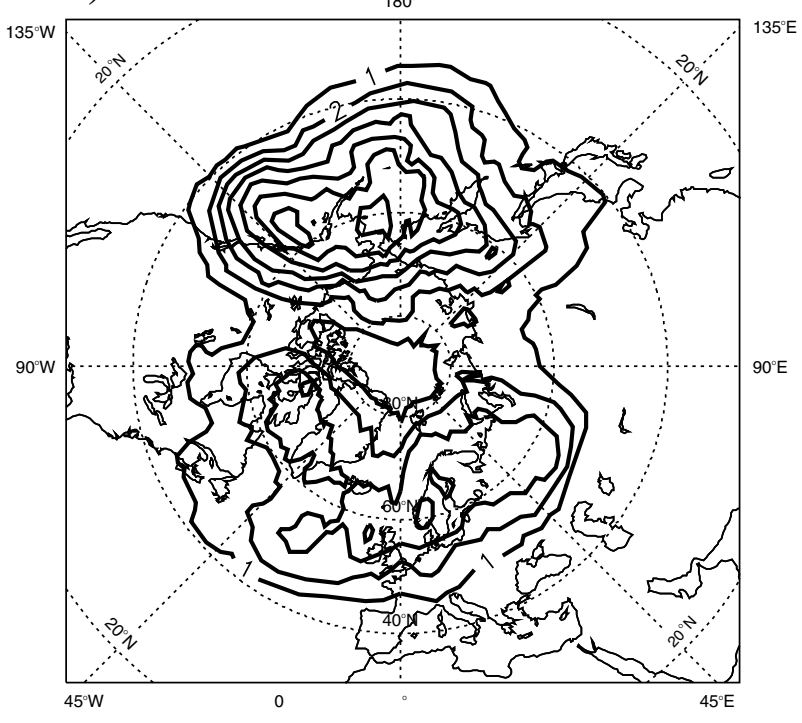

frequency estimates support the hypothesis of the enhanced detection of different types of blocking by each index.

[41] Another difference is that the frequency maximum in the Euro-Atlantic region is located over the west Atlantic by the SKS index and over the east Atlantic by the TM index (Figures 7a and 11a). Regarding maxima location, Kaas and Branstator [1993] found a blocking frequency maximum over the east Atlantic with an index based on high values of the meridional wind and persistence of the pattern. This index could be assimilated with the TM index because anomalies are not used. In order to explain the disagreement in the location of the maximum over the Euro-Atlantic the blocking signatures detected in the analyses by one index and not by the other have been computed over the WA and EA regions (Figure 13). The EA (WA) blocking signature for the events detected by the TM index and missed by the SKS algorithm are located farther east (west) than the standard signature, in agreement with the greater zonal extension of the TM blocking maximum. Conversely, both the EA and WA signatures of the blocking situations missed by the TM index and detected by the SKS index show a dipole similar to the standard signature (Figures 13b and 13d), explaining the more localized character of the SKS Euro-Atlantic signature. Figure 13 indicates the preference of the SKS index to locate the blocking frequency maximum at around $40^{\circ} \mathrm{W}$ (Figure 11a) and not farther east. Shukla and Mo [1983] concluded that $55^{\circ} \mathrm{W}$ and $145^{\circ} \mathrm{W}$ are two preferred positions for persistent ridges associated with positive geopotential anomalies. However, these ridges that the SKS index would detect could not easily fulfill the TM index criteria because of the structure of the basic state, which presents a climatological trough in these sectors. Furthermore, from the point of view of the TM index a persistent positive anomaly does not necessarily mean the existence of a blocking high. For example, if the intensity of the Iceland low is very weak compared to normal, it may show a positive anomaly, and a weaker seasonal ridge may show a negative anomaly, so that a persistent zonal flow might be interpreted as a blocking configuration. This particular situation is more easily found in the central Atlantic, preventing the detection of more situations by the SKS index in the eastern Euro-Atlantic region. Moreover, this conceptual explanation helps to understand the higher SKS frequency detected in the Pacific region. Thus the different results provided by each index might be mainly explained as due to the influence of the time-mean structure in the detection process of the blocking situations.

[42] As for the model, despite the general agreement in the seasonal evolution of blocking frequency obtained with both indices, the need of model-specific parameters for the SKS index highlights the underestimation of the anomaly amplitude instead of a wrong simulation of the anomaly persistence. The underestimation of the blocking frequency by the SKS index over the Euro-Atlantic and by the TM index over the Pacific presents a similar magnitude to the underestimation observed with the band-pass-filtered standard deviation. This may be explained again with the hypothesis of simulated blocking situations having too low amplitude. However, this might not be the only explanation. Kaas and Branstator [1993] found that blocking might be partly modulated by forcing from the mean zonal flow. They considered the relationship between

Figure 10. Wintertime mean blocking frequency computed with the SKS index for (a) the analyses, (b) ARPEGE with the index reference parameters $\left(Z_{1}=300\right.$ and $\left.Z_{2}=250\right)$, and (c) ARPEGE with the model-specific parameters $\left(Z_{1}=240\right.$ and $\left.Z_{2}=200\right)$. Contour interval is $1 \%$. 
a)

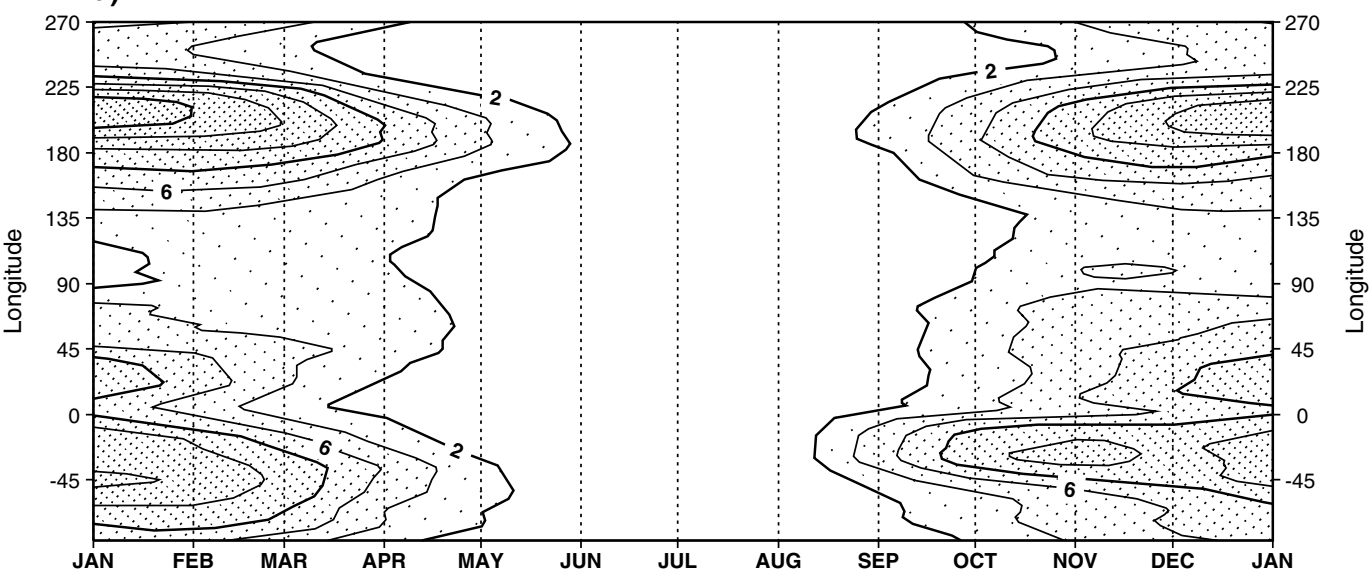

b)

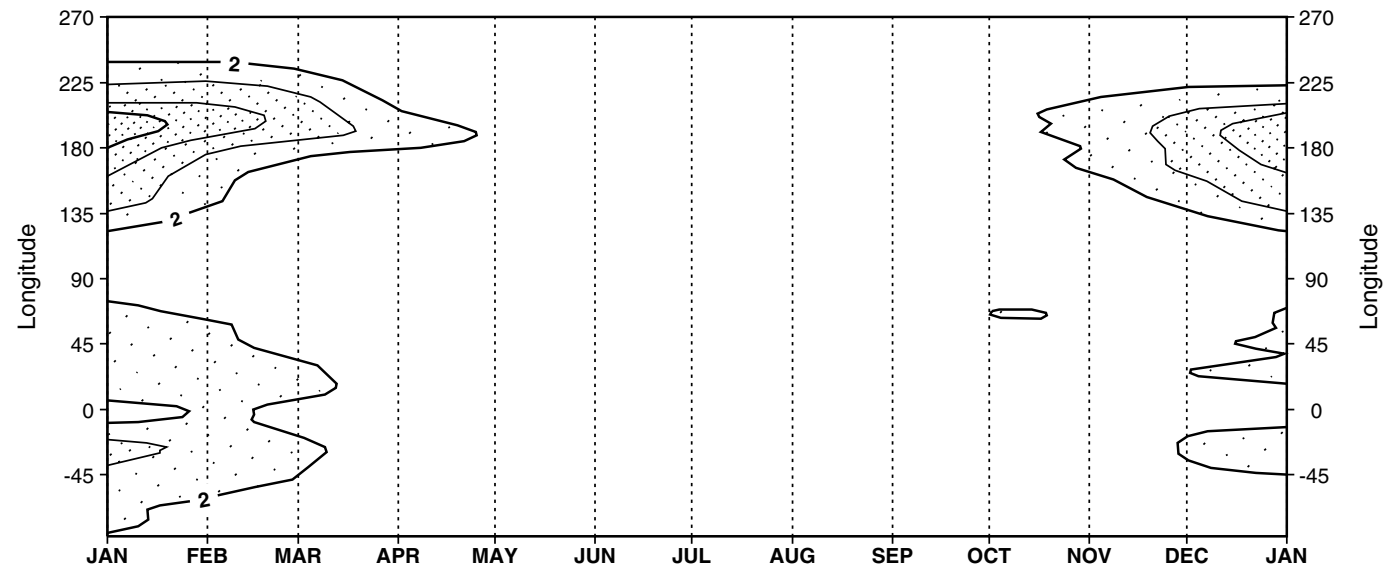

c)

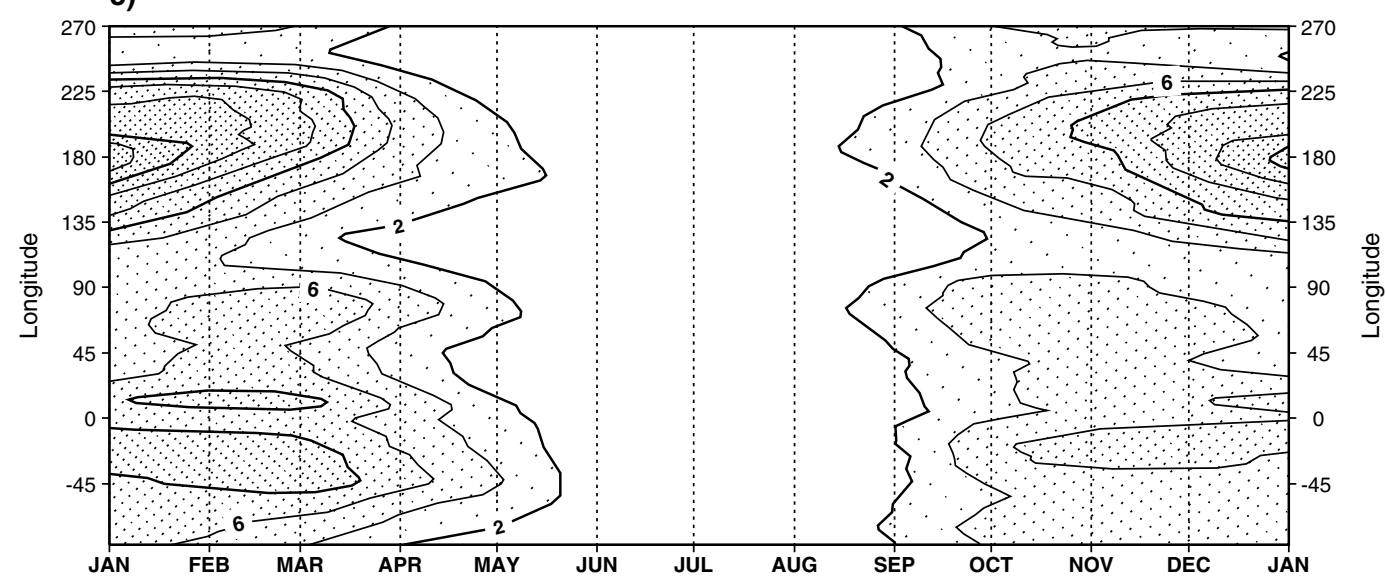

Figure 11. Mean monthly blocking frequency computed with the SKS index for (a) analyses and ARPEGE with (b) reference and (c) model-specific parameters. Areas above $2 \%$ are shaded. Contour interval is $2 \%$.

zonally averaged conditions and blocking activity as the linear low-frequency adjustment of the atmosphere to a shift in the zonal mean state. They estimated the zonal wind forcing by using the first empirical orthogonal function (EOF) of the zonal mean zonal wind. In fact, they state that both the stationary wave amplitude and the transient variability associated with blocking are affected by this zonal wind forcing. Thus the error in this kind of forcing could explain the underestimation of both features. Figure 14 shows that the zonal mean zonal wind bias for the simulation presented in this paper resembles strongly the negative phase of the forcing. This phase corresponds to a mean zonal flow configuration that produces a decrease of blocking frequency and an eastward shift of the blocking signature, as we have found for the Euro-Atlantic region.

[43] Finally, in order to show that the model simulates satisfactorily the anomaly persistence the duration of blocking events regardless of their duration has been assessed. Blocking 
Table 3a. Mean Number of Blocked Days and Mean Duration of Blocking Episodes Detected for Each Season With the SKS Index on the Analyses Using Reference Parameters ${ }^{\mathrm{a}}$

\begin{tabular}{lccccccc}
\hline & \multicolumn{3}{c}{ Blocked Episodes, days } & & \multicolumn{3}{c}{ Duration, days } \\
\cline { 2 - 4 } \cline { 6 - 8 } & ATL & PAC & SIB & & ATL & PAC & SIB \\
\hline Winter & 23 & 21 & 6 & & 8 & 9 & 8 \\
Spring & 10 & 12 & 4 & & 7 & 7 & 6 \\
Summer & 0 & 1 & 0 & & 0 & 6 & 0 \\
Fall & 14 & 7 & 4 & & 8 & 6 & 8 \\
\hline
\end{tabular}

${ }^{\mathrm{a}}$ ATL, Atlantic; PAC, Pacific; SIB, Siberian.

lifetime distribution presents an exponential decrease in Figure 15, as was also found by Dole and Gordon [1983]. The exponential decay of a blocking lifetime has been interpreted as the evidence of the independence of the probability of ending a blocking episode on its current duration [Dole and Gordon, 1983; Sausen et al., 1995]. Both indices show a very similar behavior for the two regions. In general, the model agrees fairly well with the duration of the observed blocking episodes, as was already shown in Tables 1a and 1b. The fitting of model blocking lifetime indicates that the only plausible explanation for blocking frequency underestimation might be either the small amplitude of the blocking patterns or the decrease in their frequency of occurrence and not the lack of persistence of blocking episodes.

\section{Summary and Conclusions}

[44] This work has been motivated by the observation that many climate and forecast models are unable to represent the blocking phenomenon satisfactorily. In spite of this, blocking has been traditionally used as an extratropical troposphere model validation feature. Some of the drawbacks that appear when trying to detect blocking in models through the use of indices calibrated with an observed reference have been studied in this paper. We have first investigated the properties of the indices with the ERA data and then tried to discriminate between different causes of the problems, taking into account the different phenomena involved.

[45] The 5- to 45-day band-pass-filtered standard deviation has been used as a proxy indicator of the blocking activity. It shows that the ARPEGE model underestimates blocking activity. The TM and SKS indices have been used to estimate blocking features. The standard indices offered very different results for the seasonal cycle of the blocking frequency. However, an increased agreement of the blocking frequency seasonal evolution when removing the geopotential height seasonal cycle from the data before applying the TM index has been found. The geopotential height seasonal cycle elimination accounts for the lack of seasonal evolution of the TM thresholds and corrects for some model bias. The agreement of the blocking frequency seasonal cycle is also found with the standard deviation of the band-pass-filtered data. Furthermore, although the model underestimates the number of blocking situations, a good fit has also been obtained. This is an important result because it shows that a consensus among the blocking frequency seasonal cycle estimated with two different types of indices may be reached, representing an improvement in the interpretation capabilities of the blocking seasonal cycle. However, some differences between indices still appear. The SKS index estimates of blocking frequency are lower for both the analyses and the model than the TM index estimates over the Euro-Atlantic area and higher over the Pacific. The main conclusion from this result is that an index may detect some blocking events that the other misses and vice versa. For instance, an analysis for the Euro-Atlantic area illustrates that the SKS index, as a consequence of its definition, tends to underestimate blocking events occurring over the eastern part of the region.

[46] An important consequence of the different features shown by the two blocking indices is that the estimates of blocking interannual evolution depend strongly on the index used to detect the events (not shown). The implications for model validation [Doblas-Reyes et al., 1998], blocking interannual variability [Renwick and Wallace, 1998], and blocking predictability assessment [Pavan and Doblas-Reyes, 2000] are evident. Thus an in-depth analysis of the whole simulation should be carried out before using or interpreting any blocking feature, especially for predictability studies.

[47] The results have shown that there is an overall underestimation of blocking frequency by the model. As a possible source of error we suggested the underestimation of the amplitude of the anomalies. However, Kaas and Branstator [1993] pointed out that the origin of the unrealistic blocking simulation might also be found in model systematic errors. We have shown that by removing the time-mean bias the model does, in fact, simulate realistic blocks but still with some underestimation $(20-25 \%$ of the observed value). Nevertheless, the a posteriori linear correction of the main model biases might not be enough to solve the problems in the simulation of blocking by GCMs, as shown by Sausen and Ponater [1990]. The basic state bias is shown to be the consequence of a specific zonal wind forcing associated with a decrease in the frequency of large-scale ridges over the eastern part of the main blocking regions. Wallace and Hsu [1985] arrived at a similar conclusion when studying the index cycle variability. This result stresses the importance of analyzing model blocking as a complex phenomenon with strong connections with other atmospheric features and with dynamical differences in every region.

[48] The difficulties of the model in adequately reproducing atmospheric blocking may thus be explained on the basis of three theoretical processes of blocking formation and maintenance [Hansen and Sutera, 1995]:

1. Blocking may be the result of bifurcation of the zonal flow. Verkley [1990] states that some specific mean zonal flows are needed for allowing blocking-like modons to exist. If stationary waves amplitude is underestimated, the model may be suffering from problems in nonlinear transfer of energy between large and synoptic scales and the zonal mean flow [Straus and Shukla, 1981; Reynolds et al., 1996].

2. A second hypothesis considers blocking as the result of planetary wave-wave interaction. Hansen and Sutera [1984] have shown that planetary wave energy is greater during blocking events. Lejenäs and Döös [1987] pointed out that blocking is the result of the interaction of planetary standing and traveling waves being in phase. The mechanism might well be a resonant interaction of quasi-

Table 3b. Mean Number of Blocked Days and Mean Duration of Blocking Episodes Detected for Each Season With the SKS Index on ARPEGE Using Model-Specific Parameters ${ }^{\mathrm{a}}$

\begin{tabular}{lccccccc}
\hline & \multicolumn{3}{c}{ Blocked Episodes, days } & & \multicolumn{3}{c}{ Duration, days } \\
\cline { 2 - 4 } \cline { 6 - 8 } & ATL & PAC & SIB & & ATL & PAC & SIB \\
\hline Winter & 16 & 24 & 6 & & 9 & 10 & 8 \\
Spring & 15 & 12 & 7 & & 8 & 10 & 9 \\
Summer & 0 & 0 & 0 & & 0 & 0 & 0 \\
Fall & 11 & 7 & 6 & & 8 & 9 & 8 \\
\hline
\end{tabular}

${ }^{a}$ ATL, Atlantic; PAC, Pacific; SIB, Siberian. 
ACL $6-18$ DOBLAS-REYES ET AL.: NORTHERN HEMISPHERE BLOCKING SENSITIVITY

a)

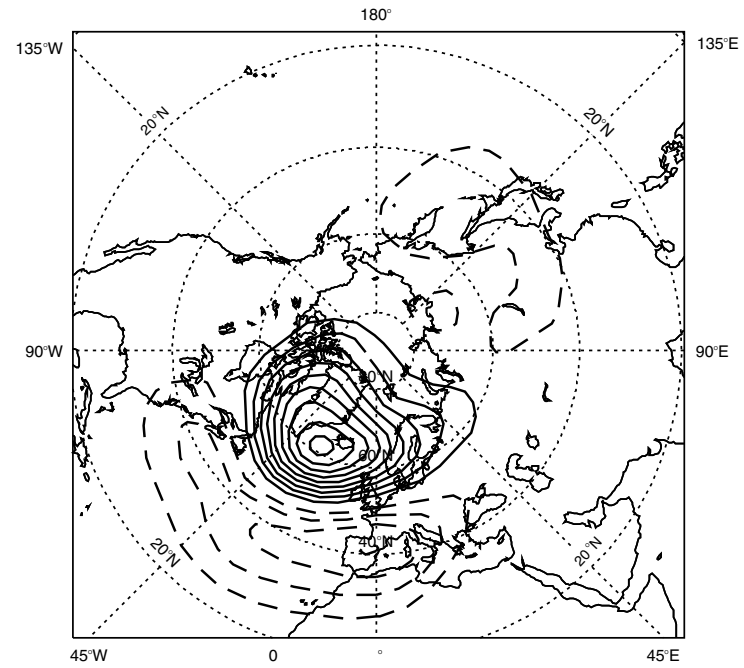

b)

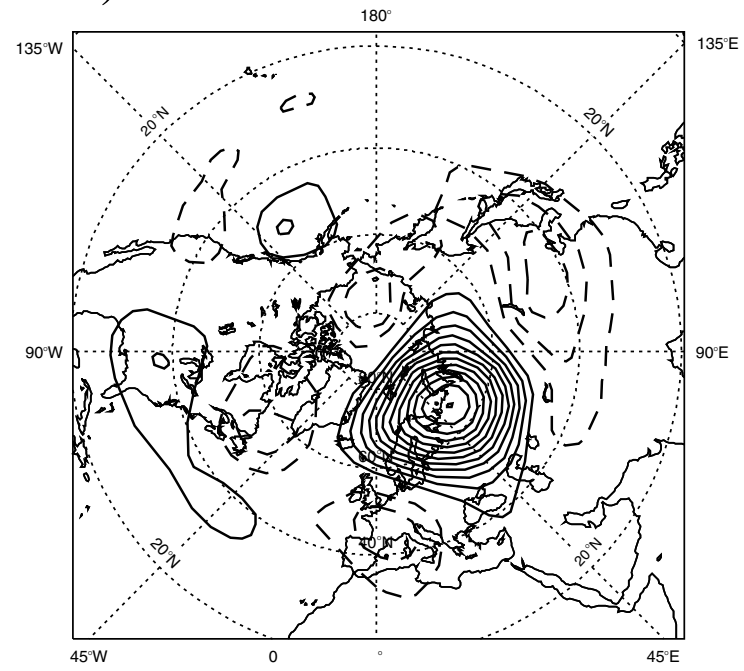

c)

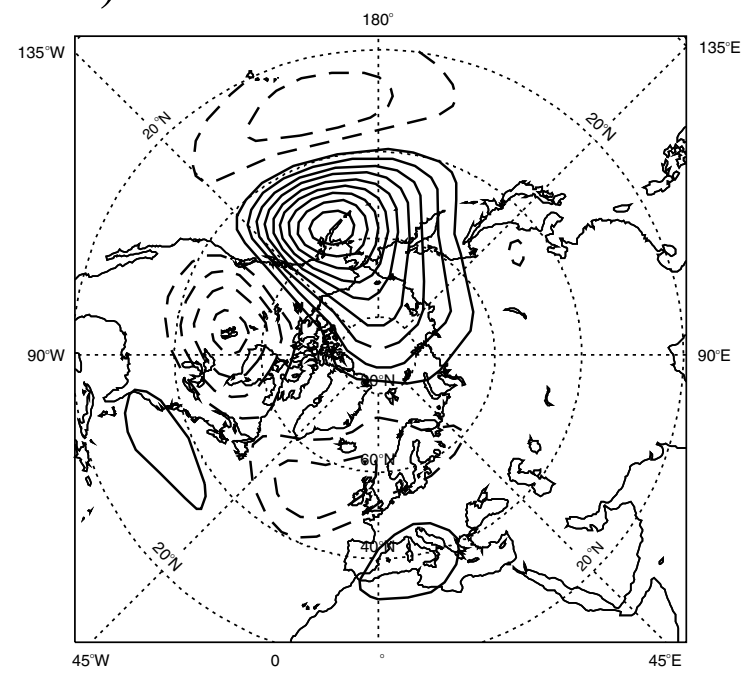

d)

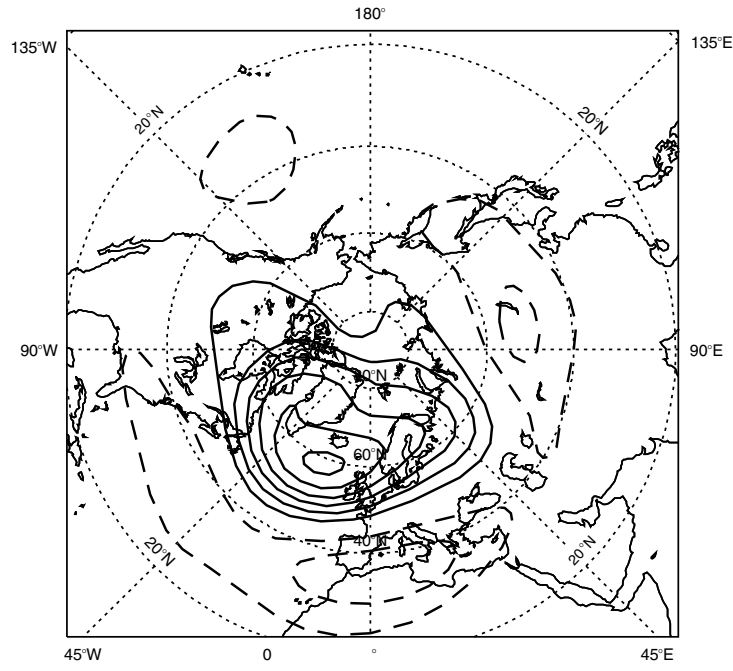

e)

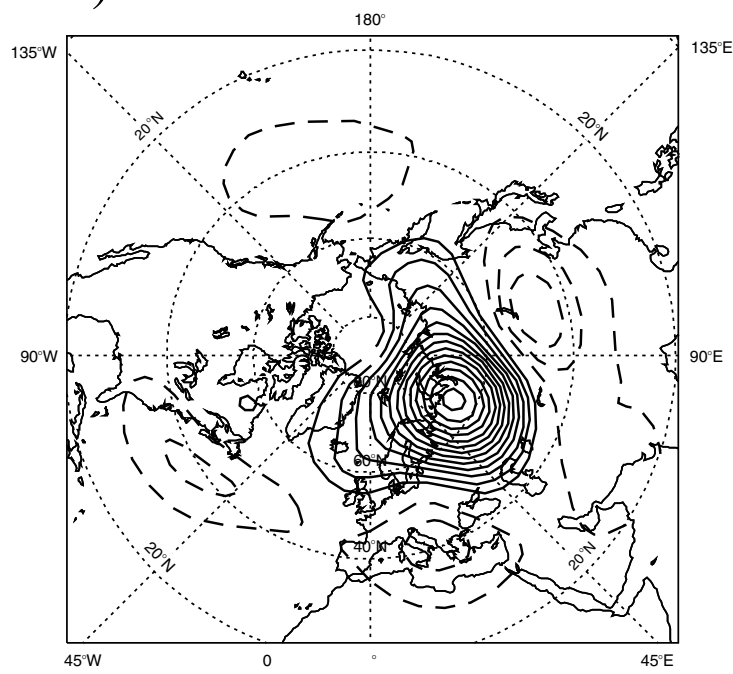

f)

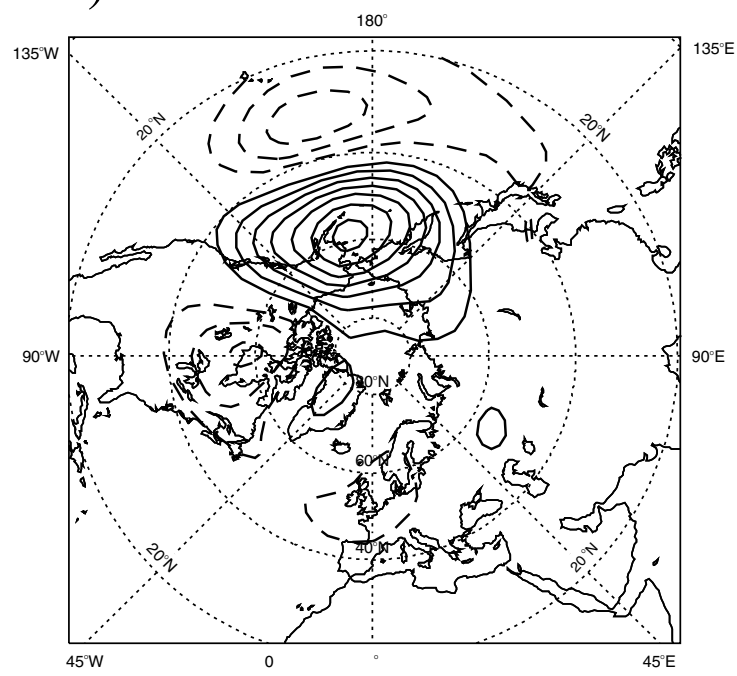


a)

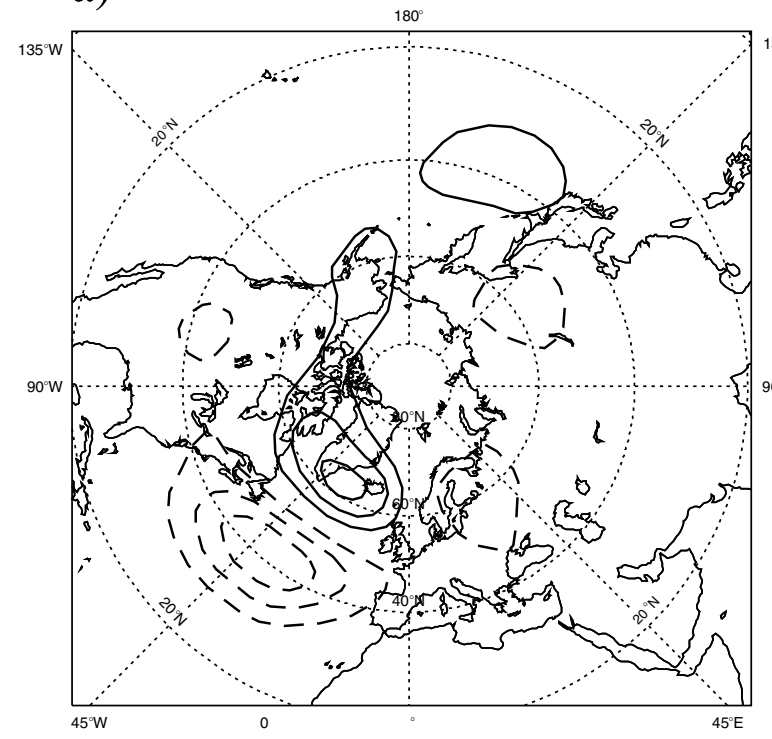

b)

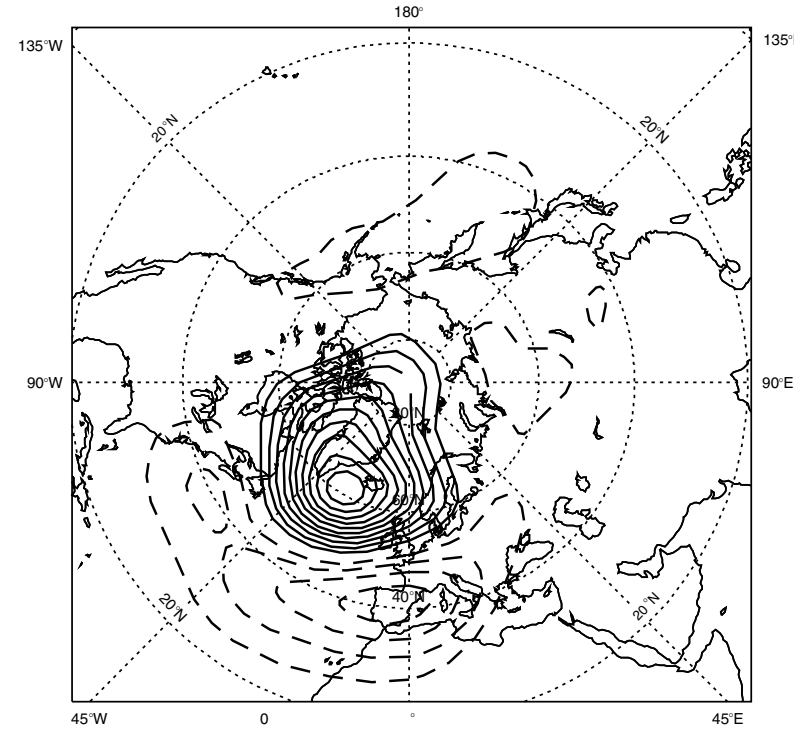

c)

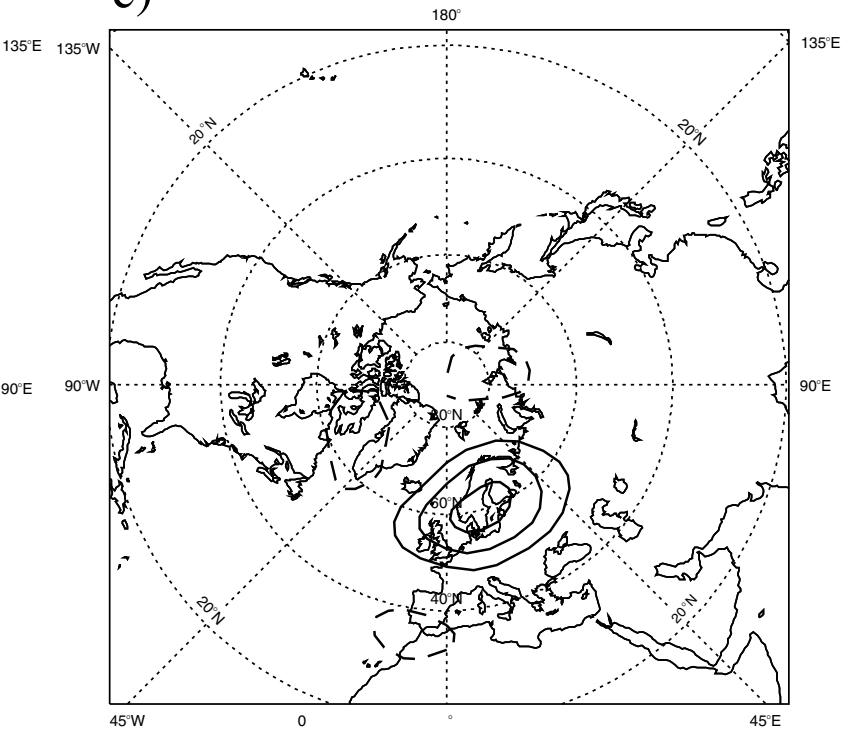

d)

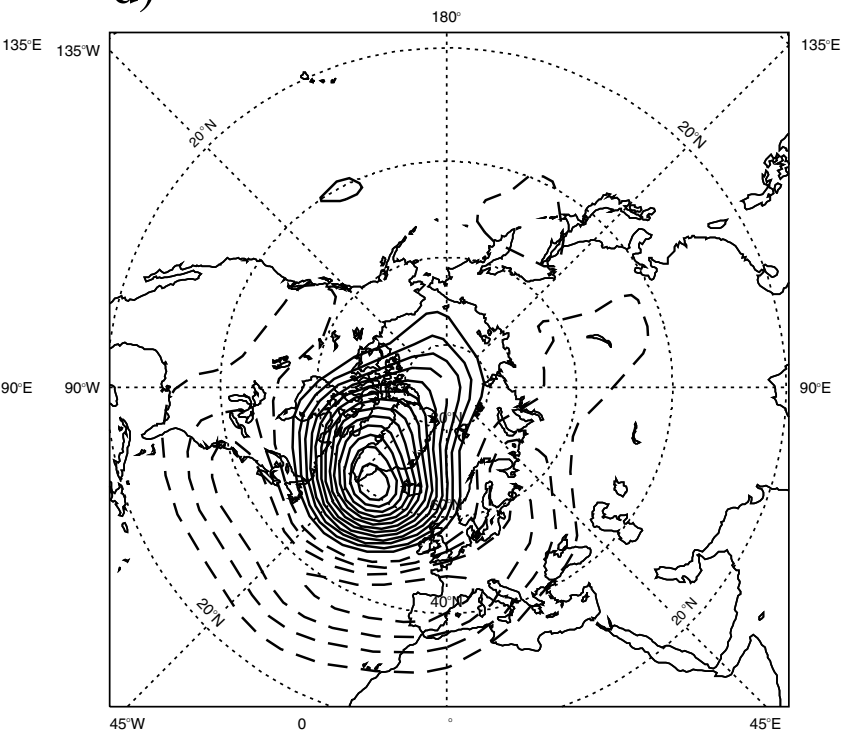

Figure 13. Wintertime blocking signatures detected in the analyses by the TM index over the regions (a) WA and (c) EA. Wintertime blocking signatures detected by the SKS index over the regions (b) WA and (d) EA. The TM index has been applied on the seasonal cycle bias-free data. The SKS index used the reference parameters. Contour interval is $50 \mathrm{~m}$. The zero isoline has been skipped.

stationary topography-generated waves, free waves, and the mean zonal flow [Egger, 1978; Da Silva and Lindzen, 1993; Marques and Rao, 2000], albeit the mutual interaction of planetary waves is able to generate by itself blocking events [Austin, 1980]. As the model underestimates the amplitude of both the stationary and transient eddies [Doblas-Reyes et al., 2001], the interaction between distinct waves may not be well represented. Kaas and Branstator's [1993] hypothesis might be included in this kind of processes.
3. Finally, blocking may a consequence of the interaction between synoptic and planetary-scale processes [Lupo and Smith, 1998]. The feedback from eddies steered by the largescale diffluent flow has been confirmed in simple models [Vautard et al., 1988] and observations [Tsou and Smith, 1990; Lupo and Smith, 1995]. Shutts [1983] proposed that the high-frequency transient eddies are defined systematically by the large-scale ambient flow in such a way that they feed back to decelerate the westerlies and help to maintain the blocking flow. Even though a deep cyclogenesis at the

Figure 12. Blocking signature in the analyses detected with the SKS index using model-specific parameters for (a) the Euro-Atlantic blocking, (b) the Siberian blocking, and (c) the Pacific blocking in winter. Plots (d), (e), and (f) display results for the corresponding three blocking sectors in the model. Contour interval is $50 \mathrm{~m}$. The zero isoline has been skipped. 


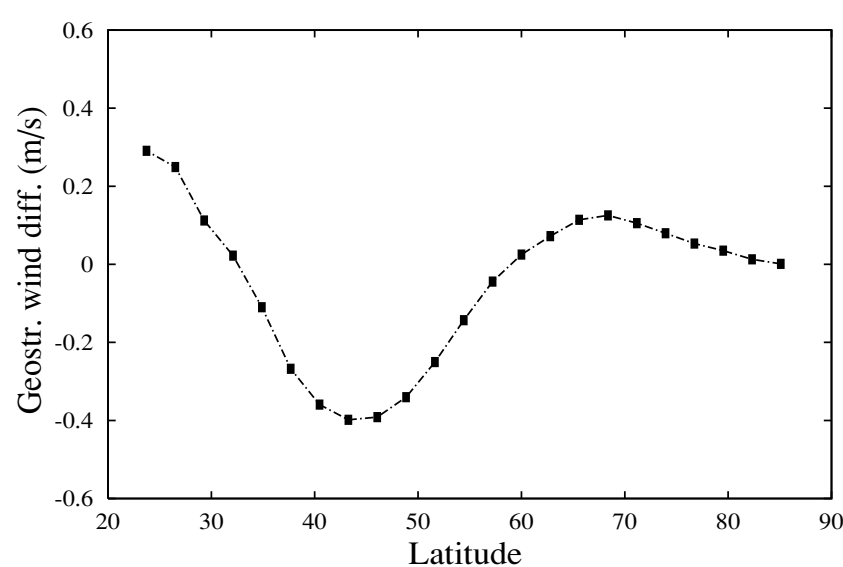

Figure 14. Wintertime $500 \mathrm{hPa}$ zonal mean zonal wind difference in winter between the analyses and ARPEGE against latitude.

western part of the storm tracks may be produced in the model, it will be not enough to develop and maintain blocking because of the underestimation of synoptic-scale variability.

[49] A careful analysis of these processes in both analyses and model simulation from a climatological point of view might enlighten most of the blocking properties. The use of indices including dynamical features, such as those based on potential vorticity, would be helpful in this task.
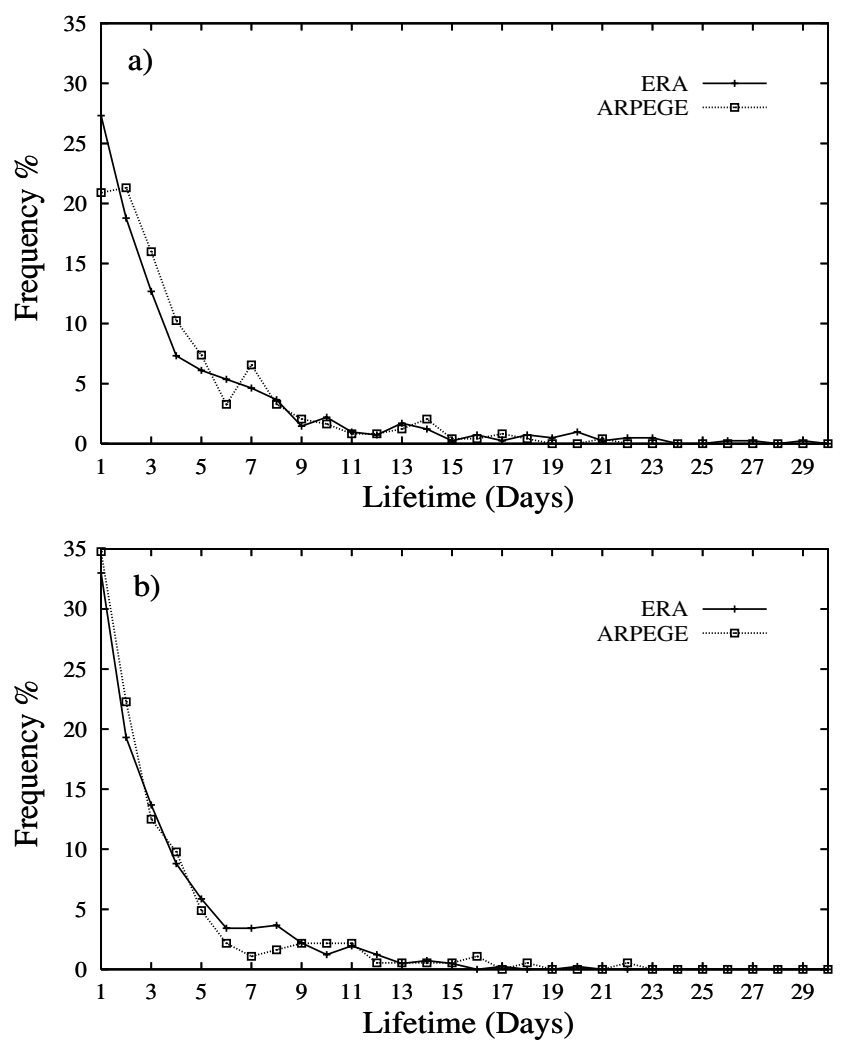

\section{Appendix A}

[50] A special estimation of the geopotential height seasonal cycle for short records has been used [Sausen et al., 1995]. Let us assume that the length of the data set is $K$ years and $N$ is the number of data points per year, so that $1 \leq t \leq K N$. A three-step procedure has been applied:

[51] Evaluation of a running annual mean with special treatment of the ends of the time series:

$$
\bar{z}_{t}=\left\{\begin{array}{lc}
\frac{1}{N+1} \sum_{u=t-N / 2}^{t+N / 2} z_{u} & N / 2<t<K N-N / 2 \\
\bar{z}_{1+N / 2} & 1 \leq t \leq N / 2 \\
\bar{z}_{K N-N / 2-1} & K N-N / 2 \leq t \leq K N
\end{array}\right.
$$

Determination of a running monthly mean of the anomaly relative to $\overline{z_{t}}, M$ being the number of data points per month:

$$
z_{t}^{*}=\left\{\begin{array}{lc}
\frac{1}{M+1} \sum_{u=t-M / 2}^{K N-M / 2}\left(z_{u}-\bar{z}_{u}\right) & M / 2<t<K N-M / 2 \\
\bar{z}_{1+M / 2} & 1 \leq t \leq M / 2 \\
\bar{z}_{K N-M / 2-1} & K N-M / 2 \leq t \leq K N
\end{array}\right.
$$

Computation of the mean seasonal cycle $z_{j}^{\prime}$ :

$$
z_{j}^{\prime}=\frac{1}{K} \sum_{u=1}^{K} z_{N(u-1)+j}^{*}
$$
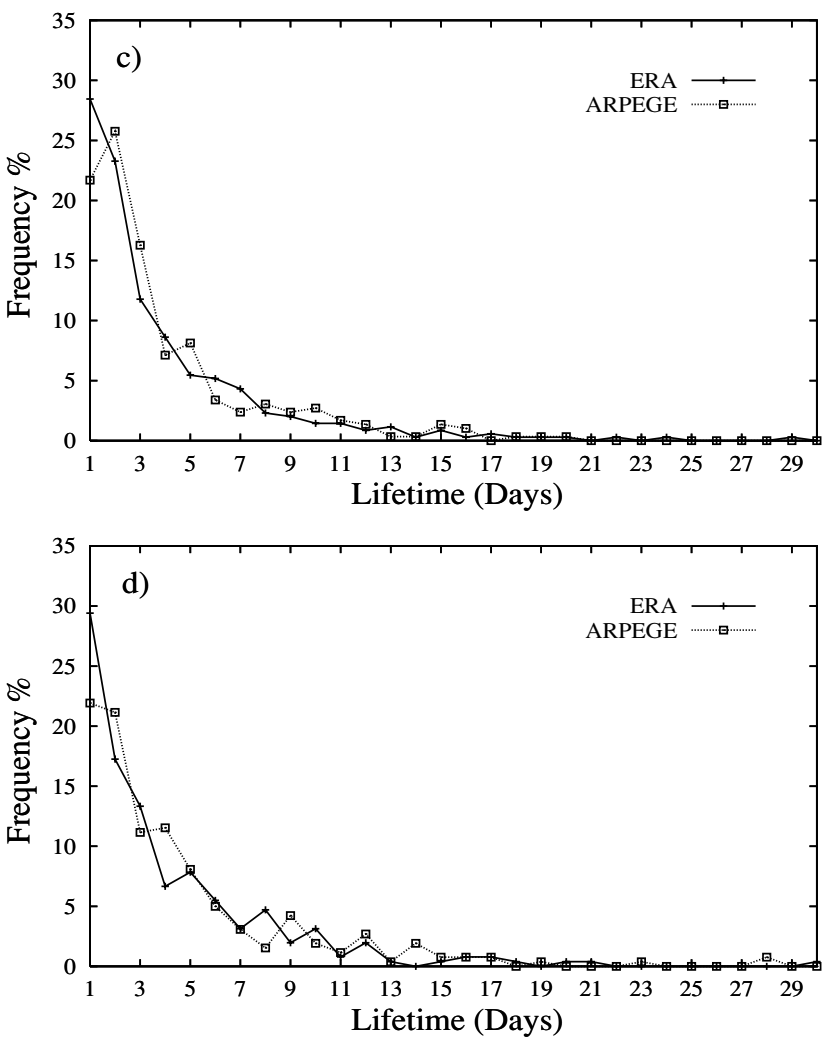

Figure 15. Frequency of winter blocking events detected with the TM index (a and b) and the SKS index (c and d) as a function of their duration for the analyses (solid lines) and ARPEGE (dashed lines; SKS index uses the modelspecific parameters). Results for the Euro-Atlantic ( $a$ and c) and the Pacific (b and d) regions are shown. 
[52] Acknowledgments. The authors are indebted to the personnel at Météo-France and ECMWF responsible for the development and running of ARPEGE. Special thanks go to Alain Braun for his valuable technical support, to David Jackson for carefully reading previous versions of the manuscript, and to M. Déqué, F. Valero, and David B. Stephenson for very interesting and useful discussions. The comments of an anonymous referee contributed to a notable improvement to this paper. This work has been supported in part by the European Commission in the framework of the Environment and Climate Research Programme (MERCURE, ENV4CT97-0485 for FJDR) and by the Spanish CICYT CLI97-0558 grant.

\section{References}

Anderson, J. L., The climatology of blocking in a numerical forecast model, J. Clim., 6, 1041-1056, 1993.

Austin, J. F., The blocking of middle latitude westerly winds by planetary waves, Q. J. R. Meteorol. Soc., 106, 327-350, 1980.

Barnston, A. G., and R. E. Livezey, Classification, seasonality and persistence of low-frequency atmospheric circulation patterns, Mon. Weather Rev., 115, 1083-1126, 1987.

Barnston, A. G., and H. van den Dool, Toward understanding the causes of low-frequency variability: The interannual standard deviation of monthly mean 700-mb height, J. Clim., 6, 2083-2102, 1993.

Blackmon, M. L., Y. H. Lee, and J. M. Wallace, Horizontal structure of 500 mb height fluctuations with long, intermediate and short time scales, J. Atmos. Sci., 41, 961-979, 1984.

Brankovic, C., and L. Ferranti, Seasonal integrations with realistic boundary forcing, paper presented at the ECMWF Workshop on New Developments in Predictability, Eur. Cent. for Medium-Range Weather Forecasting, Reading, England, 1992

Brezowski, H., H. Flohn, and P. Hess, Some remarks on the climatology of blocking action, Tellus, 3, 191-197, 1951

Buongioannini, P., S. Corti, and S. Tibaldi, An intercomparison between low-frequency variability indices, Tellus, Ser. A, 51, 773-789, 1999

Corti, S., A. Giannini, S. Tibaldi, and F. Molteni, Patterns of low-frequency variability in a three-level quasi-geostrophic model, Clim. Dyn., 13, 883904, 1997.

D’Andrea, F., La variabilité atmosphérique à basse fréquence comme problème de faible dimension, Ph.D. thesis, 162 pp., Univ. Pierre et Marie Curie, Paris, 1999.

D'Andrea, F., et al., Northern Hemisphere atmospheric blocking as simulated by 15 atmospheric general circulation models in the period 1979 1988, WCRP-96, WMO/TD- 784, 68 pp., World Meteorol. Org., Geneva, 1996.

D'Andrea, F., et al., Northern Hemisphere atmospheric blocking as simulated by 15 atmospheric general circulation models in the period 19791988, Clim. Dyn., 14, 385-407, 1998.

Da Silva, A. M., and R. S. Lindzen, On the establishment of stationary wave in the Northern Hemisphere winter, J. Atmos. Sci., 50, 43-61, 1993 .

Davis, R. E., B. P. Hayden, D. A. Gay, W. L. Phillips, and G. V. Jones, The North Atlantic subtropical anticyclone, J. Clim., 10, 728-743, 1997.

Déqué, M., and J. P. Piedelievre, High resolution climate simulation over Europe, Clim. Dyn., 11, 321-339, 1995.

Déqué, M., C. Dreveton, A. Braun, and D. Cariolle, The ARPEGE/IFS atmosphere model: A contribution to the French community climate modelling, Clim. Dyn., 10, 249-266, 1994.

Doblas-Reyes, F. J., and M. Déqué, A flexible bandpass filtering procedure applied to midlatitude intraseasonal variability, Mon. Weather Rev., 126, 3326-3335, 1998.

Doblas-Reyes, F. J., M. Déqué, F. Valero, and D. B. Stephenson, NorthAtlantic wintertime intraseasonal variability and its sensitivity to GCM horizontal resolution, Tellus, Ser. A, 50, 573-595, 1998.

Doblas-Reyes, F. J., M. A. Pastor, M. J. Casado, and M. Déqué, Wintertime westward-traveling planetary-scale perturbations over the Euro-Atlantic region, Clim. Dyn., 17, 811-824, 2001.

Dole, R. M., Persistent anomalies of the extratropical Northern Hemisphere wintertime circulation: Structure, Mon. Weather Rev., 114, 178-207, 1986.

Dole, R. M., and N. D. Gordon, Persistent anomalies of the extra-tropical Northern Hemisphere wintertime circulation: Geographical distribution and regional persistence characteristics, Mon. Weather Rev., 111, 1567-1586, 1983.

Douville, H., S. Planton, J. F. Royer, D. B. Stephenson, S. Tyteca, L. Kergoat, S. Lafont, and R. A. Betts, The importance of vegetation feedbacks in doubled- $\mathrm{CO}_{2}$ time-slice experiments, J. Geophys. Res., 105, 14,841-14,861, 2000.

Egger, J., Dynamics of blocking highs, J. Atmos. Sci., 35, 1788-1801, 1978 .

Elliott, R. D., and T. B. Smith, A study of the effects of large blocking highs on the general circulation of the Northern Hemisphere westerlies, J. Meteorol., 6, 67-85, 1949 .

Hansen, A. R., and A. Sutera, A comparison of spectral energy and enstrophy budgets of blocking versus nonblocking periods, Tellus, Ser. A, 36, 52-63, 1984.

Hansen, A. R., and A. Sutera, Large amplitude flow anomalies in Northern Hemisphere midlatitudes, J. Atmos. Sci., 52, 2133-2151, 1995.

Held, I. M., Stationary and quasi-stationary eddies in the extratropical troposphere: Theory, in Large-Scale Dynamical Processes in the Atmosphere, edited by B. J. Hoskins, and R. P. Pearce, pp. 127-168, Academic, San Diego, Calif., 1983.

Holstag, A. A. M., and B. A. Boville, Local versus non-local boundary diffusion in a global climate model, J. Clim., 6, 1825-1842, 1993.

Hoskins, B. J., I. N. James, and G. H. White, The shape, propagation and mean-flow interaction of large-scale weather systems, J. Atmos. Sci., 40, 1595-1612, 1983.

Hurrell, J. W., and H. J. van Loon, A modulation of the hemispheric annual cycle in the Southern Hemisphere, Tellus, Ser. A, 46, 325-338, 1994.

Huth, R. , On the ability (or inability?) of GCMs to reproduce continentalscale circulation, in Contemporary Climatology, edited by R. Brazdil, and M. Kolar, pp. 255-260, Masaryk Univ., Brno, Czech Republic, 1994.

Illari, L., A diagnostic study of potential vorticity in a warm blocking anticyclone, J. Atmos. Sci., 41, 3518-3525, 1984.

Kaas, E., and G. Branstator, The relationship between a zonal index and blocking activity, J. Atmos. Sci., 50, 3061-3077, 1993.

Knox, J. L., and J. E. Hay, Blocking signatures in the Northern Hemisphere: Rationale and identification, Atmos. Ocean, 22, 36-47, 1984.

Legras, B., and M. Ghil, Persistent anomalies, blocking and variations in atmospheric predictability, J. Atmos. Sci., 42, 433-471, 1985.

Lejenäs, H., Characteristics of Southern Hemisphere blocking as determined from a time series of observational data, $Q$. J. R. Meteorol. Soc., 110, 967-979, 1984.

Lejenäs, H., and B. R. Döös, The behaviour of the stationary and travelling planetary-scale waves during blocking-A Northern Hemisphere data study, J. Meteorol. Soc. Jpn., 65, 709-725, 1987.

Lejenäs, H., and H. Økland, Characteristics of Northern Hemisphere blocking as determined from a long time series of observational data, Tellus, Ser. $A, 35,350-362,1983$

Liu, Q., On the definition and persistence of blocking, Tellus, Ser. A, 46, 286-298, 1994

Lorant, V., and J. F. Royer, Sensitivity of equatorial convection to horizontal resolution in aqua-planet simulations with a variable-resolution GCM, Mon. Weather Rev., in press, 2001.

Lupo, A. R., and P. J. Smith, Climatological features of blocking anticylones in the Northern Hemisphere, Tellus, Ser. A, 47, 439-456, 1995.

Lupo, A. R., and P. J. Smith, The interactions between a midlatitude blocking anticyclone and synoptic-scale cyclones that occurred during the summer season, Mon. Weather Rev., 126, 502-515, 1998.

Marques, R. F. C., and V. B. Rao, Interannual variations of blocking in the Southern Hemisphere and their energetics, J. Atmos. Sci., 105, 46254636, 2000.

Michelangeli, P.-A., R. Vautard, and B. Legras, Weather regimes: Recurrence and quasi-stationarity, J. Atmos. Sci., 52, 1237-1256, 1995.

Miyakoda, K., and J. Sirutis, Subgrid scale physics in 1-month forecasts, II, Systematic error and blocking forecasts, Mon. Weather Rev., 118, 10651081, 1990.

Mullen, S. L., The local balances of vorticity and heat for blocking anticyclones in a spectral general circulation model, J. Atmos. Sci., 43, 14061441, 1986

Mullen, S. L., Transient eddy forcing of blocking flow, J. Atmos. Sci., 44, 3-22, 1987

Nakamura, H. , Rotational evolution of potential vorticity associated with a strong blocking flow configuration over Europe, Geophys. Res. Lett., 21, 2003-2006, 1994.

Pavan, V., and F. J. Doblas-Reyes, Multi-model seasonal forecasts over the Euro-Atlantic: Skill scores and dynamic features, Clim. Dyn., 16, 611625,2000

Quesada, V., F. J. Doblas-Reyes, and F. Valero, Caracterización de situaciones persistentes y su relación con la precipitación, in Situaciones de Riesgo Climático en España, edited by José Creus, pp. 187-196, Consejo Superior de Investigaciones Científicas, Almeria, Spain, 1995.

Randel, W. J., and I. M. Held, Phase speed spectra of transient eddy fluxes and critical layer absorption, J. Atmos. Sci., 48, 688-697, 1991.

Renwick, J. A., ENSO-related variability in the frequency of South Pacific blocking, Mon. Weather Rev., 126, 2071-2076, 1996.

Renwick, J. A., and J. M. Wallace, Relationships between North Pacific wintertime blocking, El Niño, and the PNA pattern, Mon. Weather Rev., 124, 2071-2076, 1998

Rex, D. F., Blocking action in the middle troposphere and its effect upon regional climate, I, An aerological study of blocking, Tellus, 2, 196-211, 1950 . 
Reynolds, C., R. Gelaro, and T. Murphree, Observed and simulated Northern Hemisphere intraseasonal circulation anomalies and the influence of model bias, Mon. Weather Rev., 124, 1100-1118, 1996.

Ricard, J. L., and J. F. Royer, A statistical cloud scheme for use in an AGCM, Ann. Geophys., 11, 1095-1115, 1993.

Rutland, J., and H. Fuenzalida, Synoptic aspects of the central Chile rainfall varaibility associated with the Southern Oscillation, Int. J. Climatol., 11, 63-76, 1991.

Sausen, R., and M. Ponater, Reducing the initial drift of a GCM, Contrib. Atmos. Phys., 63, 15-24, 1990.

Sausen, R., W. König, and W. F. Sielmann, Analysis of blocking events from observations and ECHAM model simulations, Tellus, Ser. A, 47, 421-438, 1995.

Shukla, J., and K. C. Mo, Seasonal and geographical variation of blocking, Mon. Weather Rev., 111, 388-404, 1983.

Shutts, G. J., The propagation of eddies in diffluent jetstreams: Eddy vorticity forcing of blocking flow fields, Q. J. R. Meteorol. Soc., 109, 737761, 1983.

Sinclair, M. R., A climatology of anticyclones and blocking for the Southern Hemisphere, Mon. Weather Rev., 124, 245-263, 1996.

Straus, D. M., and J. Shukla, Space-time structure of a GLAS general circulation model and a comparison with observations, J. Atmos. Sci., 38, 902-917, 1981 .

Tibaldi, S., and L. R. Ji, On the effect of model resolution on numerical simulation of blocking, Tellus, Ser. A, 35, 28-38, 1983.

Tibaldi, S., and F. Molteni, On the operational predictability of blocking, Tellus, Ser. A, 42, 343-365, 1990.

Tibaldi, S., T. Palmer, C. Brankovic, and U. Cubasch, Extended-range predictions with ECMWF models: Influence of horizontal resolution on systematic error and forecast skill, Q.J. R. Meteorol. Soc., 116, 835-866, 1990.

Tibaldi, S., E. Tosi, A. Navarra, and L. Pedulli, Northern and Southern Hemisphere seasonal variability of blocking frequency and predictability, Mon. Weather Rev., 122, 1971-2003, 1994.

Tibaldi, S., P. Ruti, E. Tosi, and M. Maruca, Operational predictability of winter blocking at ECMWF: An update, Ann. Geophys., 13, 305-317, 1995.

Tibaldi, S., F. D'Andrea, E. Tosi, and E. Roeckner, Climatology of Northern Hemisphere blocking in the ECHAM model, Clim. Dyn., 13, 649666, 1997.

Tracton, M. S., Predictability and its relationship to scale interaction processes in blocking, Mon. Weather Rev., 118, 1666-1695, 1990.

Trenberth, K. E., and K. C. Mo, Blocking in the Southern Hemisphere, Mon. Wea. Rev., 113, 3-21, 1985.

Tsou, C.-H., and P. J. Smith, The role of synoptic/planetary-scale interaction during the development of a blocking anticyclone, Tellus, Ser. A, 42, 174-193, 1990

van Loon, H., J. W. Kidson, and B. Mullan, Decadal variation of the annual cycle in the Australian dataset, J. Clim., 6, 1227-1231, 1993.

Vautard, R., Multiple weather regimes over the North Atlantic: Analysis of precursors and successors, Mon. Weather Rev., 118, 2056-2081, 1990.

Vautard, R., and B. Legras, On the source of midlatitude low-frequency variability, II, Nonlinear equilibration of weather regimes, J. Atmos. Sci., 45, 2845-2867, 1988.

Vautard, R., B. Legras, and M. Déqué, On the source of midlatitude lowfrequency variability, I, A statistical approach to persistence, J. Atmos. Sci., 45, 2811-2843, 1988.

Verkley, W. T. M., Modons with uniform absolute vorticity, J. Atmos. Sci., 47, 727-745, 1990

Wallace, J. M., and H.-H Hsu, Another look at the index cycle, Tellus, Ser. $A, 37,478-486,1985$.

M. J. Casado and M. A. Pastor, Instituto Nacional de Meteorología, Paseo de las Moreras s/n, E-28040 Madrid, Spain. (icd@inm.es; ice@inm.es)

F. J. Doblas-Reyes, Seasonal Forecast Group, European Centre for Medium-Range Weather Forecasting, Shinfield Park, Reading RG2 9AX, UK. (f.doblas-reyes@ecmwf.int) 